\section{Homogeneous Catalysis by Gold}

\author{
A. Stephen K. Hashmi \\ Institut für Organische Chemie, Universität Stuttgart, \\ Pfaffenwaldring 55, D-70569 Stuttgart, Germany \\ http://www.hashmi.de
}

\begin{abstract}
A comprehensive overview in the field of homogeneous catalysis by gold is given and the basic principles are discussed. It is also highlighted where homogeneous gold catalysts are already superior to other catalysts and where future possibilities for advantageous use of homogeneous gold catalysts exist.
\end{abstract}

For a long time, gold was considered to possess only low catalytic activity ("catalytically dead") and therefore only its stoichiometric co-ordination and organo-metallic chemistry was investigated intensively. Even in the 19th century it was quite popular to characterize precious alkaloid bases after their troublesome isolation from natural sources as tetrachloroaurates $(1,2)$.

Since then, a change of paradigm has taken place (3). Among the numerous applications for gold, its use as a catalyst, albeit not yet consuming large amounts of this metal, has attracted much attention. Overall, in the chemical databases ca. 230,000 papers on gold can be found, of which about 9,000 deal with gold catalysis (from the SciFinder database in October 2003). The field of gold catalysis is dominated by heterogeneous catalysts, while homogeneous catalysts still represent the much smaller part (about 100 hits). Still, a significant amount of different homogeneous gold-catalysed reactions is known and basic principles can be deduced from them.

In this article only publications in which gold is unambiguously the site of the catalysis reaction will be covered. This, for example, excludes the use of some mixed metal clusters and mixed metal colloids.

\section{Background}

Homogeneous catalysis includes all reactions in which the substrate(s) and the catalyst are in the same state. As there exists only a limited number of highly volatile gold compounds, most of these reactions are conducted in the liquid phase with either liquid or dissolved substrate(s) and a dissolved catalyst. Homogeneous catalysis in the solid state, a part of the solvent-free reactions (4) that are nowadays quite popular in the field of green chemistry, has not been explored with gold yet (with the exception shown in Figure $31)$ ! In this context, the non-toxicity of gold, which helps to avoid any environmental problems, is also of importance.

The catalyst itself promotes a chemical reaction, a process in which chemical compounds (the substrates) are converted to other chemical compounds (the products), to proceed under milder reaction conditions (lower temperatures, lower pressure, lower concentrations of the substrates, higher or different selectivity). As the catalyst is not consumed, a catalytic amount is sufficient - but this is often a matter of debate: for some scientists 20 mol\% of 'catalyst' are still catalytic, while others may consider this to be a substoichiometric reaction and accept only $0.001 \mathrm{~mol} \%$ or less as catalytic.

Two motives drive the desire to produce a chemical reaction:

1 A chemical compound is unwanted (for example 


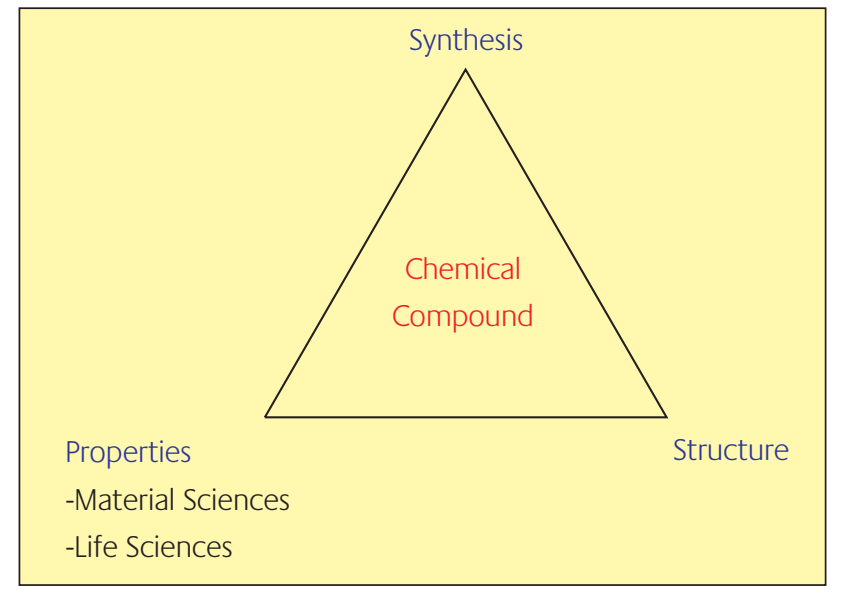

\section{Figure 1}

The three important features of chemical compounds

poisonous) and is converted to environmentally acceptable compounds (waste management).

2 A desired chemical compound is produced that way (synthesis of bulk or fine chemicals). With chemical compounds always three things are associated: their synthesis, their structure and their properties. The need for chemical compounds stems from their properties in either the field of materials science or life science.

As always in life, costs are crucial.

The use of gold as a catalyst is desirable when it has a similar activity as for a more expensive catalyst, when it shows a higher activity or a higher selectivity than less expensive catalysts and when a completely new chemical transformation is possible using the gold catalyst.

In the past century the number of publications on gold catalysis per year has increased exponentially (Figure 2). While the absolute numbers are not debatable, one should ask what this really means. In every conference similar graphs are presented and one learns that the number of publications in that specific field shows exponential growth. How can that be, every field is getting more important? The explanation is simple, the number of scientific publications itself resembles an exponential growth. So the exponential growth of the sheer number of publications on gold catalysis itself might only mean that the field is keeping pace with all the other fields (for all publications in the field of chemistry, see Figure 3). Whether the field is able to claim a higher percentage of all chemical publications and thus has truly gained in significance can be determined by normalization. The division of the numbers in Figure 2 by the numbers in Figure 3 gives the numbers in Figure 4. The good news is that indeed gold catalysis has occupied an increasing portion of the chemical literature, since the 80 's roughly a $400 \%$ increase has taken place!

The following sections are arranged in the sequence in which the reaction principles were first discovered. All later

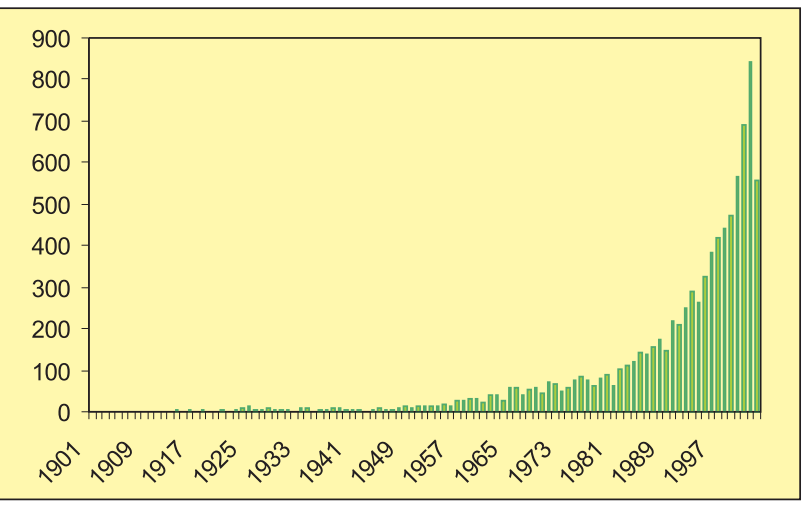

Figure 2

Total number of publications on gold catalysis per year

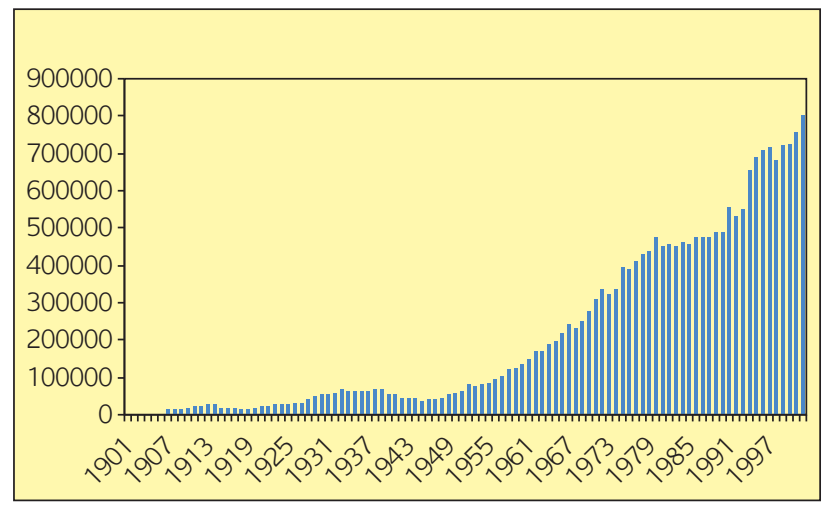

Figure 3

Total number of all chemical publications per year

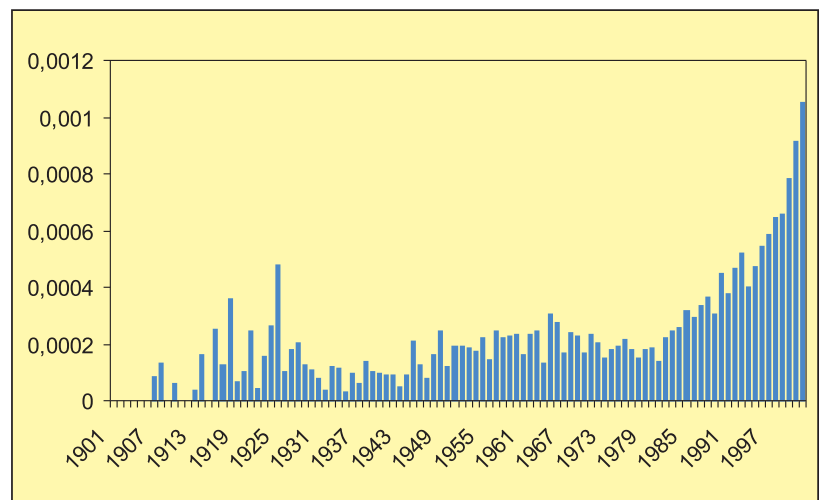

Figure 4

Normalized number (percentage of all chemical publications) of publications on gold catalysis per year

variations or related reactions are then placed in the same section. The turnover numbers (TON) and turnover frequencies (TOF) can be deduced from the amount of catalyst and the yield. The important new bonds formed in the catalysis reactions are highlighted in red. 


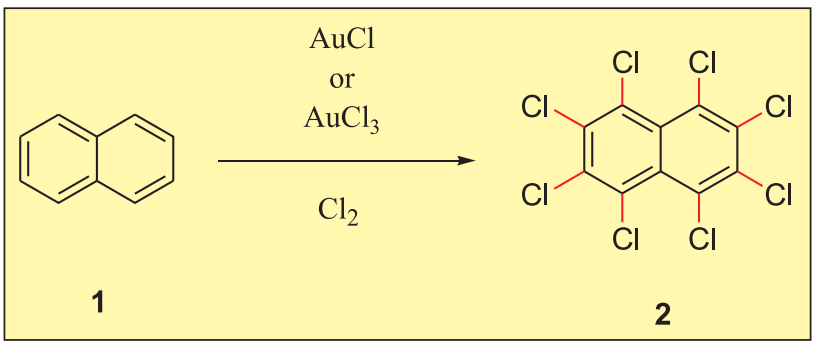

Figure 5

Complete substitution of all hydrogen atoms of napthalene by chlorine

\section{The Beginning}

In 1935, it was reported that both $\mathrm{AuCl}$ and $\mathrm{AuCl}_{3}$ catalyse the chlorination of naphthalene $\mathbf{1}$ to octachloronaphthalene 2 (5), Figure 5.

The authors found gold to be among the most active catalysts, but as we know today, other Lewis-acid catalysts such as $\mathrm{FeCl}_{3}$ are superior for these reactions.

\section{Strained Compounds}

In 1972, gold was still considered to possess low reactivity, thus the investigation of a highly reactive substrate was quite logical. Several different late transition metals were assessed for the isomerisation of the bicyclo[1.1.0]butane 3. With $\mathrm{Aul}_{3}$ at $0^{\circ} \mathrm{C}$ four products 4-7 were obtained, Figure 6. $\mathrm{PdCl}_{2}$, which is a $d^{8}$-system like $A u(I I)$, gives an analogous product ratio, while for example $\mathrm{RhCl}_{3} \bullet \mathrm{H}_{2} \mathrm{O}$ produced an entirely different product distribution (6).

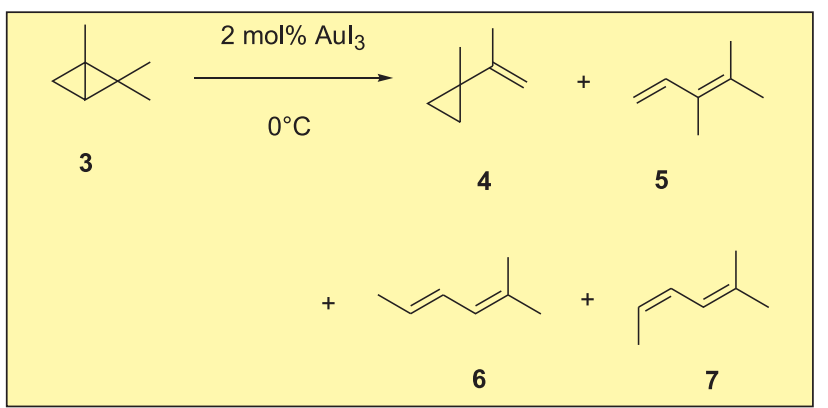

\section{Figure 6}

Four different products from the isomerisation of an unsymmetrical bicyclo[1.1.0]butane

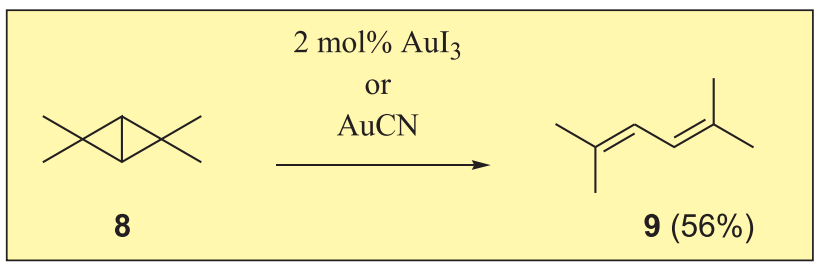

Figure 7

Only one product from the symmetric bicyclo[1.1.0]butane
The symmetric bicyclo[1.1.0]butane $\mathbf{8}$ provided only one product 9, Figure 7. Here $\mathrm{Aul}_{3}$ induced a much faster reaction than AuCN; but the best yield was obtained with $\mathrm{Cu}\left(\mathrm{BF}_{4}\right)_{2} \bullet \mathrm{H}_{2} \mathrm{O}$.

In 1976, de Meijere et al. wanted to investigate the thermolysis of diamedane $\mathbf{1 0}$ to triquinacene $\mathbf{1 1}$. A reactor with a gold surface was built, in the expectation that this surface would be inert. To their surprise they discovered that snoutene 12 was formed, Figure 8. Subsequently, they found that not only the gold surface but also gold complexes e.g. AuCl $\left(\mathrm{C}_{10} \mathrm{H}_{12}\right) \quad\left(\mathrm{C}_{10} \mathrm{H}_{12}=\right.$ dicyclopentadiene $)$ are capable of catalysing this conversion (7).

\section{Oxidation Reactions}

This area of investigation was initiated by Natile et al. in 1983. The selective oxidation of thioethers 13 to sulfoxides 14 with gold, known as a stoichiometric reaction since 1905 (8), can be achieved in a catalytic manner using a gold terachloroaurate in the presence of $\mathrm{HNO}_{3}(9,10)$, Figure 9 .

The chemoselectivity of the reaction was high, and the presence of vinyl groups, tertiary amines, alcohols and diols was tolerated. With chiral thioethers a single diastereomer of the product was detected. Subsequently it was discovered that the corresponding tetrabromoaurate was even more active (11).

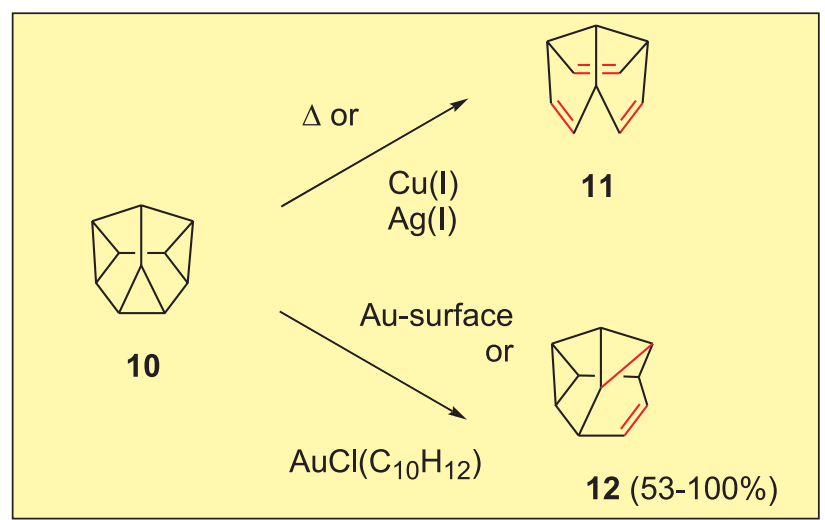

Figure 8

Even the surface of elemental gold was active

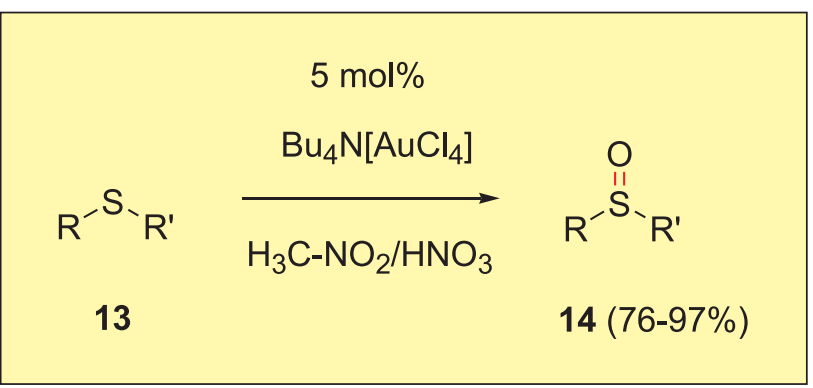

Figure 9

Highly selective oxidation of thioethers 


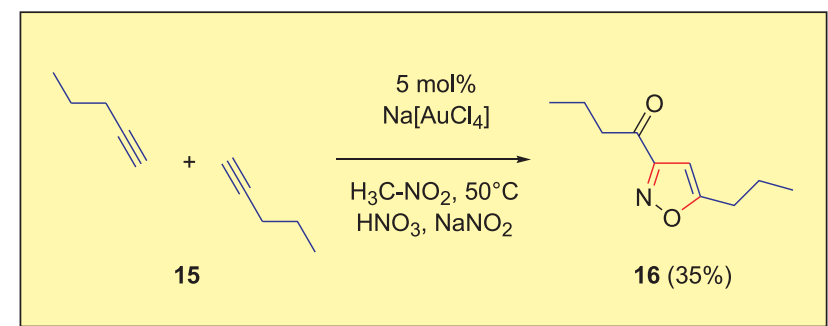

Figure 10

Synthesis of isoxazoles under oxidative conditions

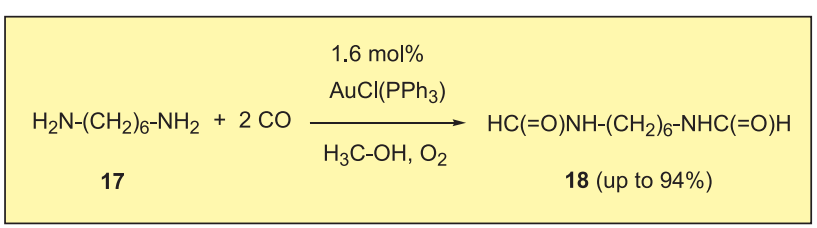

Figure 11

Synthesis of formamides from CO under oxidative conditions

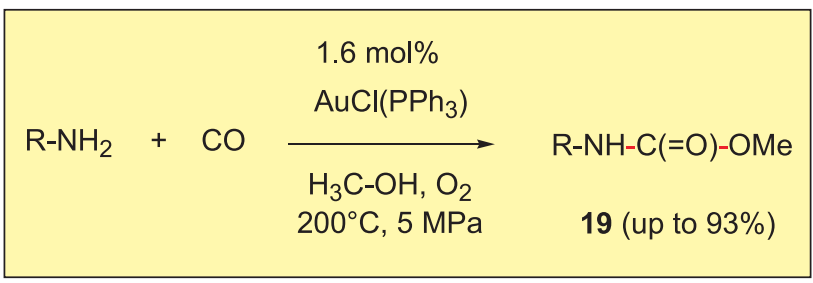

Figure 12

Synthesis of carbamates from CO under more forcing oxidative conditions

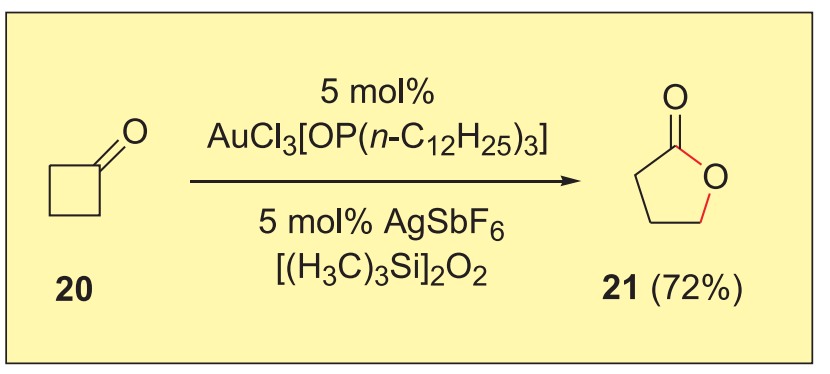

Figure 13

Baeyer-Villiger oxidation to cyclic lactones $\mathbf{2 1}$

A true breakthrough was finally achieved by Hill et al. who used a combinatorial catalyst design and discovered that with $\mathrm{H}\left[\mathrm{AuCl} \mathrm{Cl}_{4}\right] / \mathrm{AgNO}_{3}$ in acetonitrile under 1 atmosphere of oxygen or even air can be used as the oxidant for the reaction of 13 to 14 (12). This catalyst system had an activity orders of magnitude higher than the previously most reactive $\mathrm{Ru}(\mathrm{II})$ (13) or Ce(IV) (14) complexes.

The synthesis of isoxazoles $\mathbf{1 6}$ from two terminal alkynes 15 and $\mathrm{a} \mathrm{HNO}_{3} / \mathrm{NaNO}_{2}$ oxidation system with $\mathrm{Na}\left[\mathrm{AuCl}_{4}\right]$ was discovered by Natile et al. (15), Figure 10.

The latter reaction used the knowledge that alkynes are excellent substrates for gold catalysts. This had been recognised several years before by Utimoto et al., see the next but one section.

The oxidative carbonylation of amines $\mathbf{1 7}$ to formamides 18 was achieved using $\mathrm{AuCl}\left(\mathrm{PPh}_{3}\right)$ as catalyst and oxygen as oxidant (16), Figure 11. This gold complex had been used three years earlier by Teles et al. for the addition of oxygennucleophiles to alkynes, see the next but one section.

Nevertheless, this result was not unique for gold since palladium(II) gave comparable results. At higher temperatures and pressure with the same catalyst-system carbamates 19 were obtained (17), Figure 12.

The soluble complexes $\mathrm{Na}\left[\mathrm{AuCl}\right.$ ] and $\mathrm{AuCl}\left(\mathrm{PPh}_{3}\right)$ were reported to efficiently catalyse the oxidation of alkanes such as cyclooctane by $\mathrm{H}_{2} \mathrm{O}_{2}$ in acetonitrile at $75^{\circ} \mathrm{C}$ with a TON of 520. But the reaction was not selective, cyclooctyl hydroperoxide, cyclooctanone and cyclooctanole were obtained (18).

Further oxidations using $\mathrm{H}_{2} \mathrm{O}_{2}$ or its derivative $\left(\mathrm{Me}_{3} \mathrm{Si}_{2} \mathrm{O}_{2}\right.$ were reported by Sundermeyer et al. (19). They observed that $5 \mathrm{~mol} \%$ of both gold(I) and gold(III) complexes are active catalysts for the Baeyer-Villiger oxidation of ketones 20 (20), Figure 13. While the gold complexes had the highest activity, silver(I) complexes were also active and there was also a slow uncatalysed background reaction.

There was a spectacular report from Shilov et al. (21). A gold-containing protein ("Au-protein"), isolated from the goldophilic bacteria Micrococcus luteos, oxidises methane to methanol.

\section{C-C-Bond Formation}

The first example of a C-C-bond forming reaction catalysed by gold was the asymmetric aldol condensation developed by Ito, Hayashi et al. in 1986 (22). The addition of an isocyano acetate $\mathbf{2 3}$ to an aldehyde $\mathbf{2 2}$ produces trans-24 as the major and cis-25 as the minor product in excellent enantiomeric excess (ee) in the presence of a cationic gold catalyst and a chiral diphosphanyl ferrocene ligand, Figure 14.

This reaction had the highest impact on organic chemistry to date, and already several summarising reviews have appeared on the reaction and its application in organic synthesis $(23,24)$.

Historically it is quite interesting to note that this was the first example of a catalytic asymmetric aldol reaction (25).

Just as an example, the synthesis of D-threo-sphingosine $\mathbf{2 8}$, a membrane component, is shown in Figure 15. Here the stereoselective transformation of the aldehyde $\mathbf{2 6}$ to the oxazoline $\mathbf{2 7}$ is a key step.

The method could also be applied to $N$-tosylated aldimines, to give derivatives of enantiomerically pure $\alpha, \beta$ diamino carboxylates (26). 


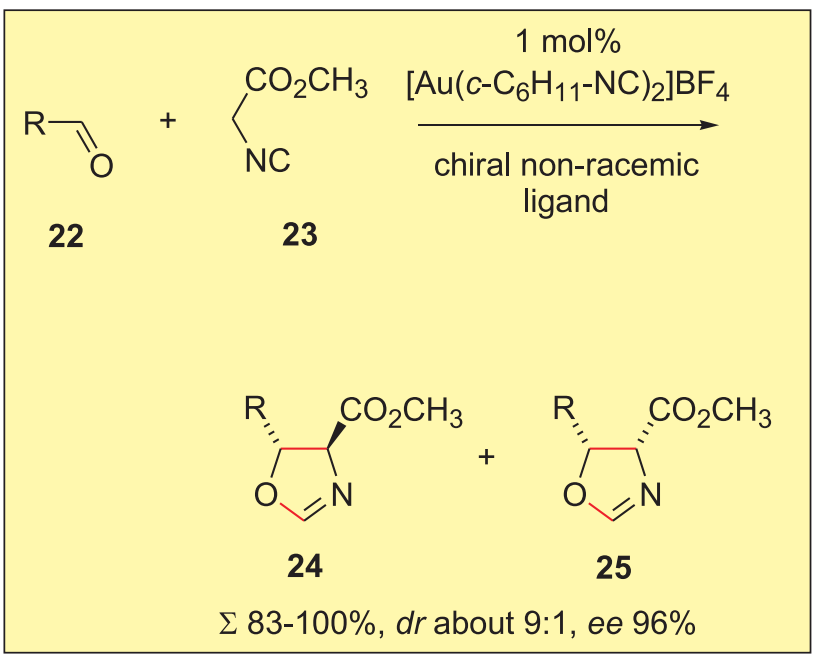

Figure 14

The very first example of a catalytic asymmetric aldol reaction ( $d r=$ diastereomeric ratio)

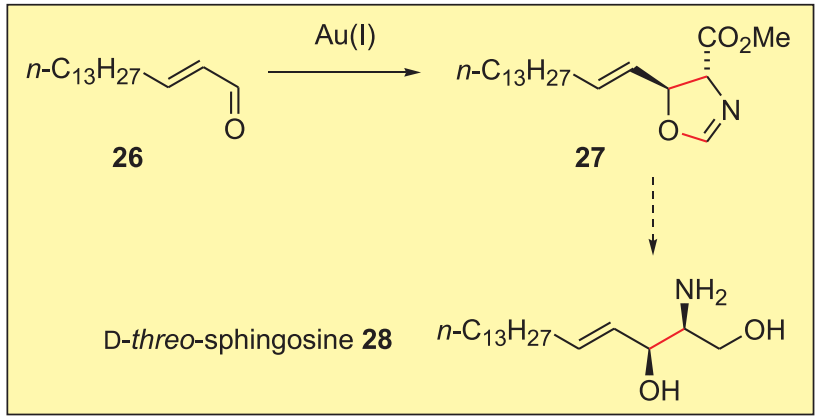

Figure 15

Key step in the synthesis of D-threo-sphingosine

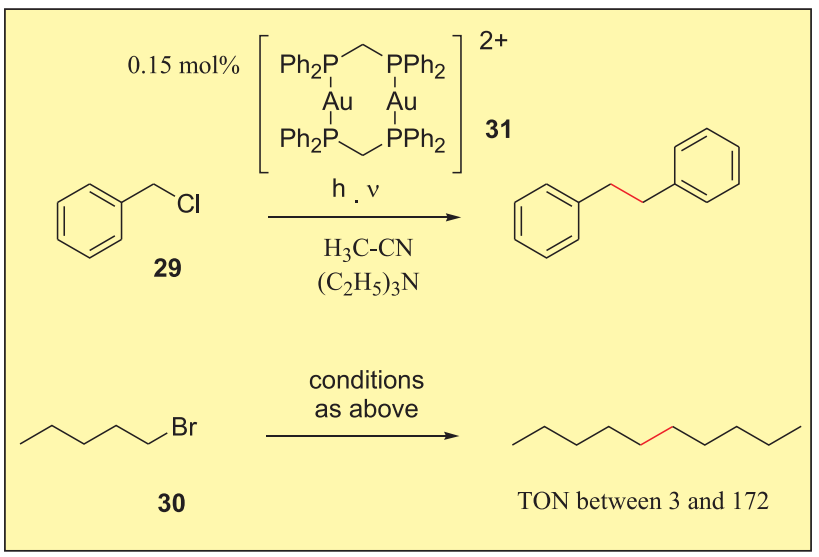

\section{Figure 16}

Photoinduced reductive dimerization

In 1992, Che et al. described a photoinduced C-C bond formation (27). As little as $0.15 \mathrm{~mol} \%$ of the dinuclear complex $\mathbf{3 1}$ upon irradiation provided dimers of alkyl halides such as benzyl chloride $\mathbf{2 9}$ or pentyl bromide $\mathbf{3 0}$, Figure 16. The turnover numbers varied from 3 to 172 . The fate of the halogens is not discussed in detail, the triethylamine might

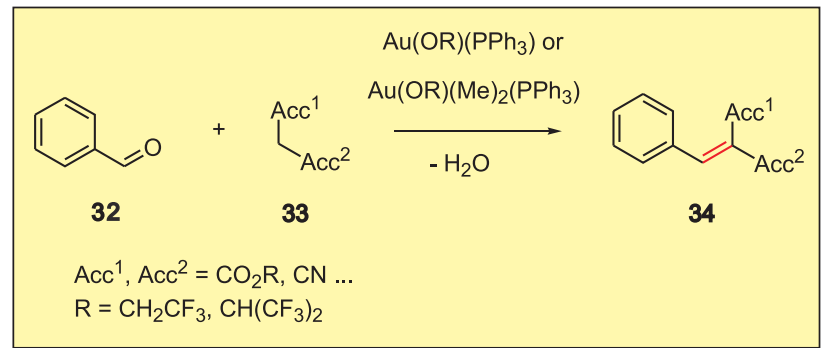

Figure 17

Knoevenagel condensations under neutral conditions

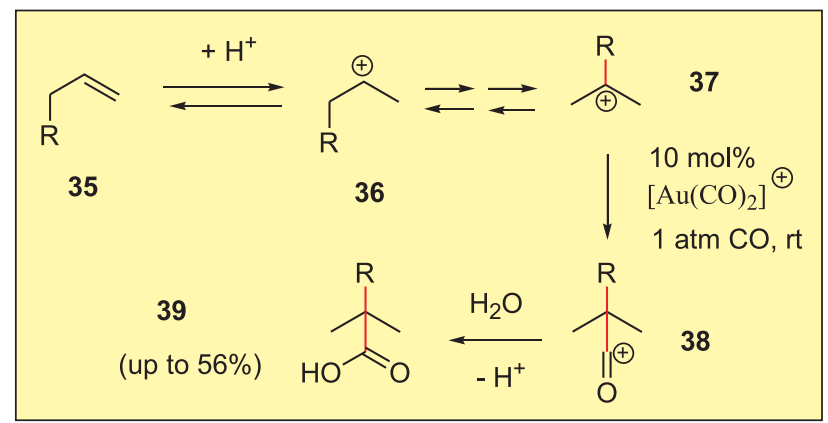

\section{Figure 18}

Koch-Haaf reactions at low CO pressure

be the reaction partner. The reaction probably proceeds via a radical mechanism.

Komiya et al. discovered that $\mathrm{Au}(\mathrm{I})$ - and $\mathrm{Au}(\mathrm{III})$-alcoholates catalyse Knoevenagel condensations under neutral conditions (28). Acceptor-substituted methylene compounds $\mathbf{3 3}$ react with aldehydes $\mathbf{3 2}$ to provide alkenes 34, Figure 17. This type of reaction where carbonyl groups react with nucleophiles, catalysed by gold, is encountered again in Figure 33 with substrate $\mathbf{8 8}$.

Subsequently, $\mathrm{Xu}$ et al. reported that terminal olefins 35 with an $\mathrm{Au}(\mathrm{I})$-catalyst, sulfuric acid $\left(\mathrm{H}_{2} \mathrm{SO}_{4}\right)$ and only one atmosphere of carbon monoxide (CO) give tertiary carboxylic acids 39 (29), Figure 18. It is assumed that the $\mathrm{H}_{2} \mathrm{SO}_{4}$ first protonates the olefin and then the secondary carbenium ion $\mathbf{3 6}$ isomerises to a more stable tertiary carbenium ion $\mathbf{3 7}$ by so-called Wagner-Meerwein rearrangements $(30,31,32)$; finally the carbon monoxide is transferred to this carbenium ion, the resulting acyl cation $\mathbf{3 8}$ is attacked by the nucleophile water and a proton is lost. Overall this transformation is a low-pressure equivalent of the Koch-Haaf reaction which normally needs up to $100 \mathrm{~atm}$. of CO (33).

The transition-metal catalysed reactions of allenyl ketones such as $\mathbf{4 0}$ give different types of products $\mathbf{4 1 , 4 2}$ and 43 (34), Figure 19. With $\mathrm{AuCl}_{3}$ the dimers 44 could be obtained as new products (35). It is also interesting to look at the reaction times; while the consumption of the starting material with $1 \mathrm{~mol} \%$ of $\mathrm{AgNO}_{3}$ took about one week and with $1 \mathrm{~mol} \%$ of $\mathrm{PdCl}_{2}(\mathrm{MeCN})_{2}$ about an hour, with $1 \mathrm{~mol} \%$ $\mathrm{AuCl}_{3}$ a complete conversion is achieved in less than 5 


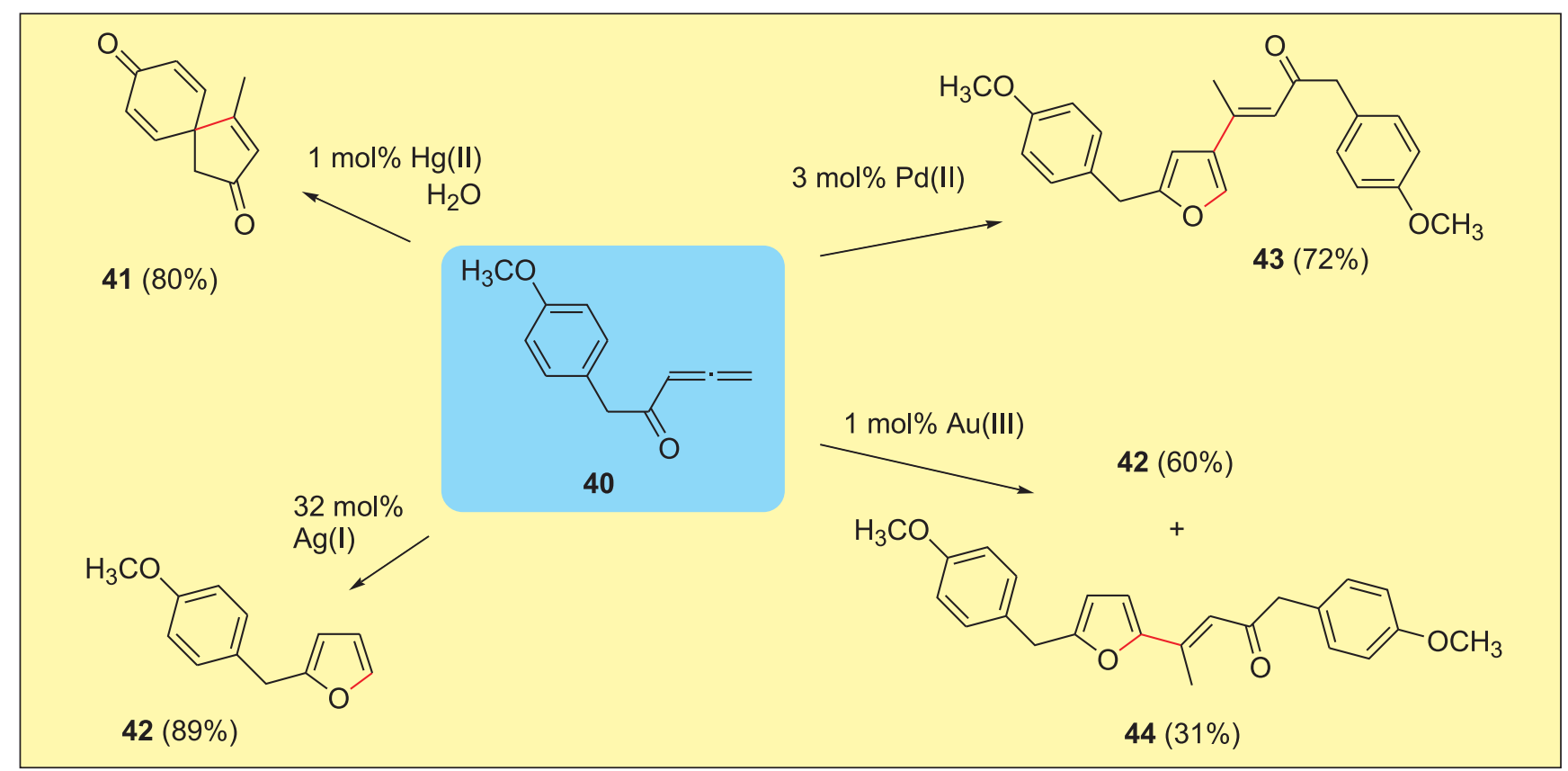

\section{Figure 19}

Allenyl ketones and different transition metal catalysts

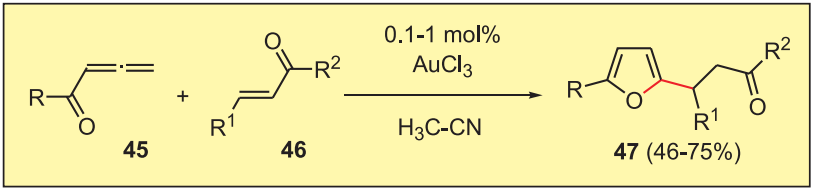

\section{Figure 20}

Selective cross-dimerization of allenyl ketones and Michael acceptors

minutes! Such faster kinetics produced by gold catalysts is not uncommon.

Furthermore, a cross-dimerization of allenyl ketones $\mathbf{4 5}$ and Michael acceptors ( $\alpha, \beta$-unsaturated ketones) 46 to substituted furans $\mathbf{4 7}$ could be achieved that way, a reaction that was impossible to achieve with the other late transition metal catalysts, Figure 20.

For the latter reaction, we could show that it is composed of two independent gold-catalysed parts, the isomerisation of the allenyl ketone $\mathbf{4 5}$ to a furan $\mathbf{4 8}$ and the reaction of $\mathbf{4 8}$ with the $\alpha, \beta$-unsaturated ketone $\mathbf{4 6}$, Figure 21 . In the first part it is remarkable that unlike palladium(II), where the organometallic intermediate is long-lived and finds time to react with a second allenyl ketone, the gold undergoes a fast proto-demetallation. In the second part two different possibilities exist, which have a common intermediate 49 . This intermediate $\mathbf{4 9}$ is the gold-analogue of the intermediate of a well-known palladium-catalysed coupling reaction, the Heck reaction (36). In the Heck reaction this intermediate subsequently undergoes $\beta$-hydrogen elimination, but in the case of gold once again the proto-demetallation is faster and the saturated product $\mathbf{4 7}$ rather than the product $\mathbf{5 0}$ is set

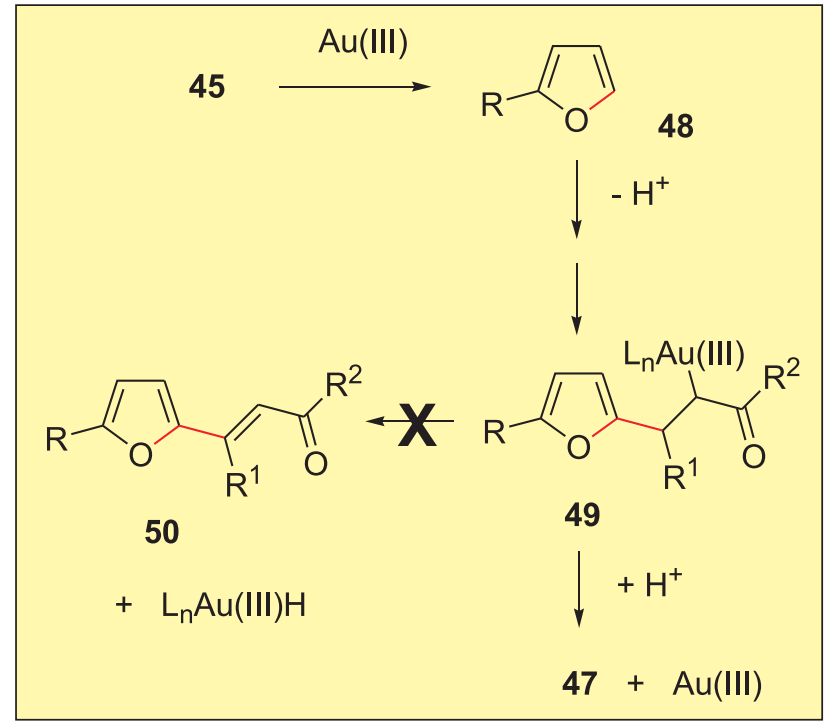

Figure 21

Proto-demetallation rather than $\beta$-hydride-elimination as characteristics of gold catalysts

free; the low tendency to form gold hydride complexes seems to be a general principle (37). Thus unlike palladium in the Heck reaction, gold does not undergo a change in oxidation state during the catalytic cycle.

Not only the heterocycle furan, but also a whole range of electron-rich benzenoid aromatic compounds can be used in such hydroarylation reactions of Michael acceptors catalysed by gold(III). Gold(I) showed lower turnover frequencies (38).

The activation of alkynes not only for the cycloisomerisation of a propargyl ketone to a furan but also 


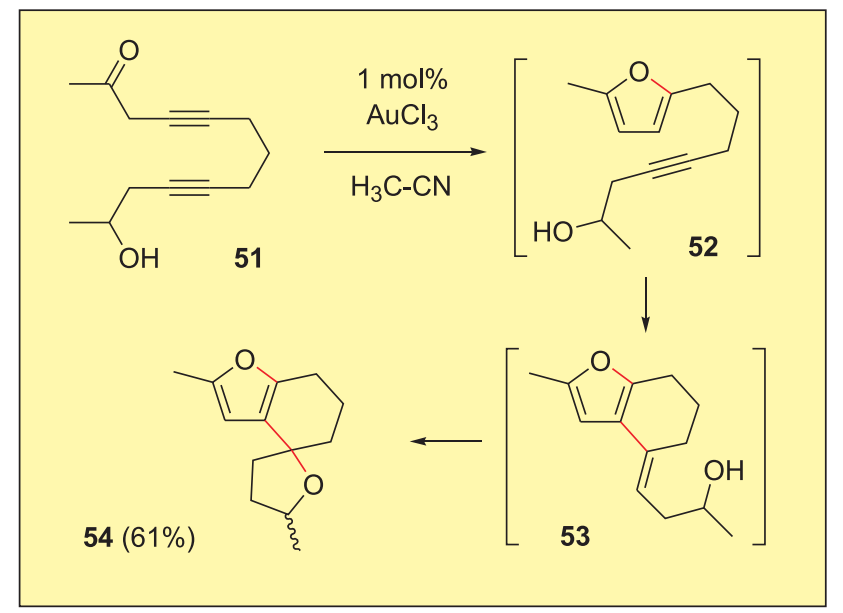

Figure 22

Cycloisomerisation, hydroarylation and nucleophilic cyclization in one step

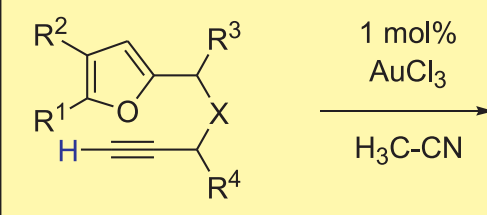

55<smiles>[R]c1cc2c(c(O)c1[R])C([R])[X]C2[R]</smiles>

$56(42-97 \%)$
$\mathrm{X}=\mathrm{O}, \mathrm{NR}^{5}, \mathrm{CR}_{2}^{5}, \mathrm{CR}_{2}{ }_{2} \mathrm{NR}^{6}, \mathrm{NR}^{5} \mathrm{CR}^{6}{ }_{2}, \ldots$

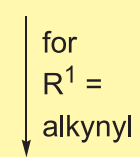

$57(48-82 \%)$<smiles>[R]c1oc2c3c(cc([R])c2c1[R])C([R])[X]C3[R]</smiles>

\section{Figure 23}

Synthesis of highly substituted phenols

for the intramolecular hydroarylation of an alkyne and, in the final step, even the intramolecular addition of an hydroxyl group to an alkene are part of the reaction of $\mathbf{5 1}$ to $\mathbf{5 4}$ via $\mathbf{5 2}$ and 53 (34), Figure 22.

The alkyne moiety is the functional group which has been most versatile in organic synthesis so far (39) as Figure 10 and numerous examples on the next pages show.

If, as in 55, not a substituted but a terminal alkyne is tethered to the furan, the reaction takes an entirely different pathway. Highly substituted phenols 56 are generated (40), Figure 23. While other late transition metals with $d^{8}$ configuration are also capable of catalysing this reaction, gold is much more active than all the other catalysts. This reaction has been applied to the synthesis of biaryl

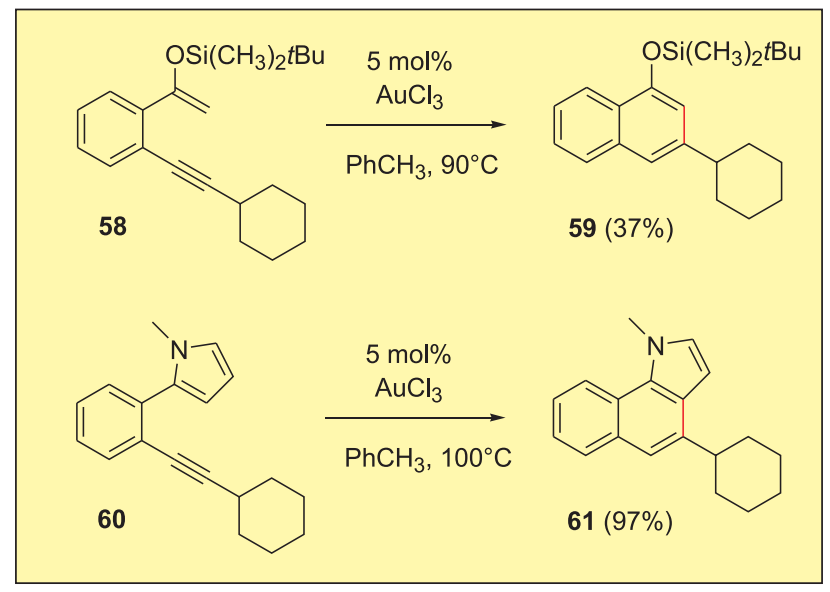

Figure 24

Further intramolecular vinylations of arenes

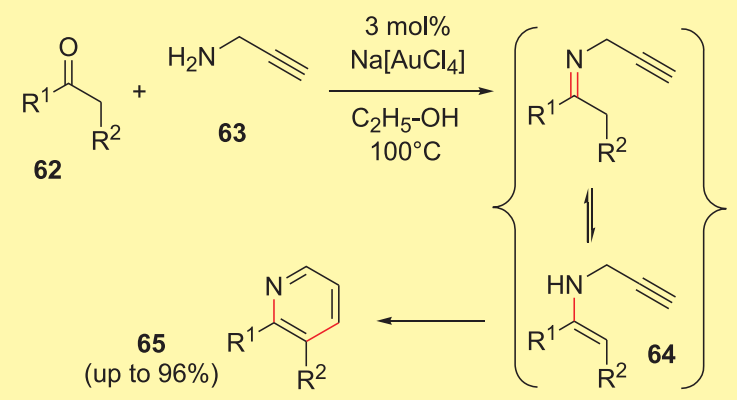

Figure $\mathbf{2 5}$

A new pyridine synthesis

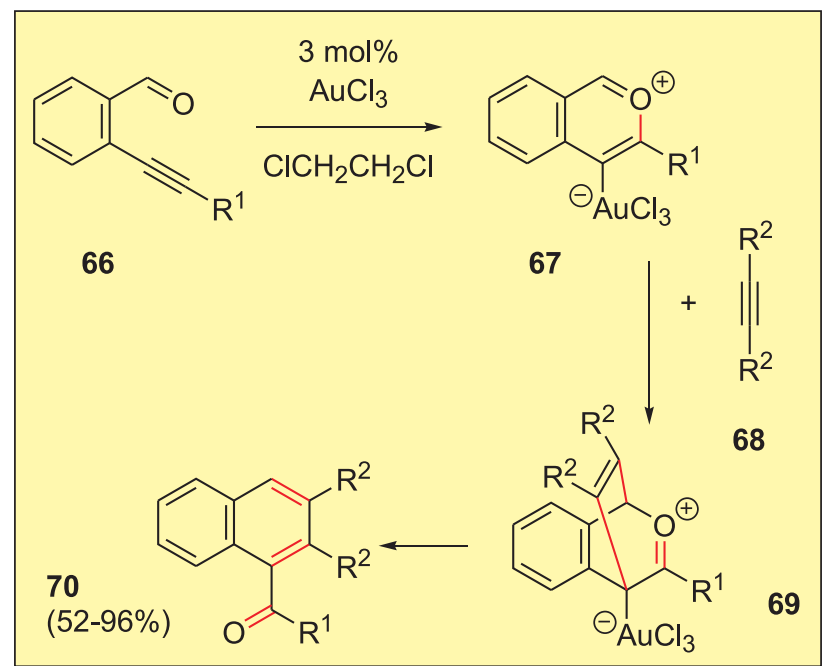

Figure 26

A new naphthalene synthesis

compounds (41), benzofurans 57 (42), recently in the total synthesis of Jungianol (43) and current work on the total synthesis of naturally occurring and pharmaceutically important tetrahydroisoquinolines $(44,45)$. 


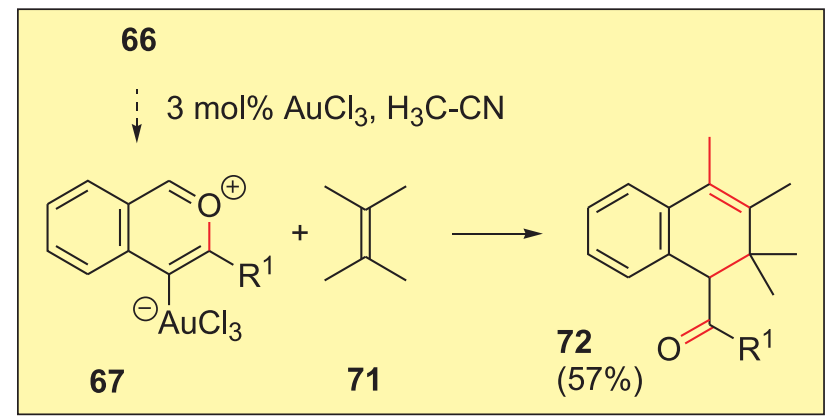

Figure 27

A dihydronapthalene synthesis

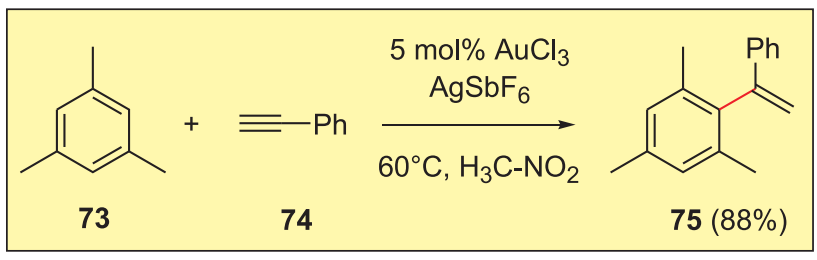

Figure 28

Intermolecular vinylation of arenes

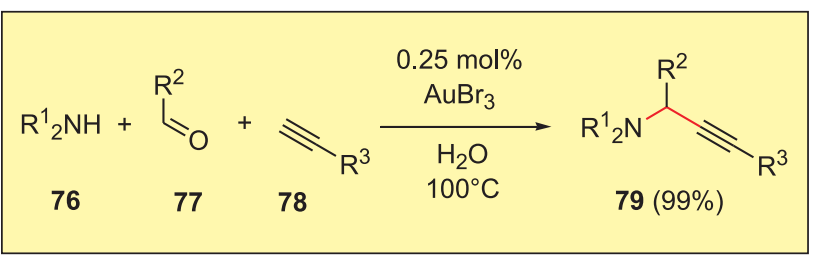

\section{Figure 29}

Synthesis of propargylamine, a three-component reaction in water

The principle mentioned above for $\mathbf{5 1}$, the electrophilic attack of an activated alkyne (activated by co-ordination to gold) at an electron rich $\pi$-system such as an enol-ether $\mathbf{5 8}$ or a pyrrole $\mathbf{6 0}$ led to napthalene $\mathbf{5 9}$ or anellated napthalene systems 61 (46), Figure 24.

The analogous reaction leading to phenanthrenes was investigated by Fürstner et al. (47). Often $\mathrm{AuCl}_{3}$ gave the highest yield and the highest chemoselectivity in comparison with $\mathrm{GaCl}_{3}, \mathrm{InCl}_{3}$ and $\mathrm{PtCl}_{2}$.

A new synthesis of pyridines $\mathbf{6 5}$, just published by Arcadi et al. (48), utilizes both the principle of the electrophilic attack of an alkyne at an electron-rich enamine in the intermediate $\mathbf{6 4}$ and in a preceding step the gold-catalysed condensation of ketones $\mathbf{6 2}$ with propargyl amines $\mathbf{6 3}$, Figure 25 (compare formation of compound 92 in Figure 33).

Another synthesis of naphthalene systems similar to $\mathbf{5 9}$, but by an entirely different route, was published by Yamamoto et al. in 2002 (49). From two different components, an orthoalkynyl benzaldehyde 66 and a disubstituted alkyne 68, 1acylnapthalenes $\mathbf{7 0}$ are produced via $\mathbf{6 7}$ and 69, Figure 26. Under similar conditions a copper(II) triflate/acid catalyst delivers only unsubstituted napthalenes (50).
Last year Dyker et al. proved that olefins such as $\mathbf{7 1}$ can also react with 67 to deliver products of type 72 (51), Figure 27.

Just recently, Reetz et al. discovered that the intermolecular variation of that reaction, terminal aryl alkynes $\mathbf{7 4}$ react with the electron-rich aromatic mesitylene $\mathbf{7 3}$ to $\mathbf{7 5}$ (52), Figure 28.

Three different components can be combined in a reaction developed by Li et al. in 2003 (53). From a secondary amine $\mathbf{7 6}$, an aldehyde $\mathbf{7 7}$ and a terminal alkyne $\mathbf{7 8}$ the tertiary propargyl amine $\mathbf{7 9}$ is obtained in high yields in water as the solvent, Figure 29.

Li et al. were also the first to use $\mathrm{AuBr}_{3}$ as the catalyst, which is in fact slightly cheaper per mol than $\mathrm{AuCl}_{3}$. Yamamoto et al. (50) have already taken up this idea in their recent investigation of the naphthalene synthesis already cited above.

Furthermore, water was the optimal solvent for that reaction, which is most remarkable in the context of the addition of water to alkynes described below.

\section{Activation of C-C-Multiple Bonds for the Addition of $\mathrm{N}$ - and $\mathrm{O}$-Nucleophiles}

The activation of C-C-multiple bonds for the addition of nucleophiles by late transition metal species such as Pd(II)

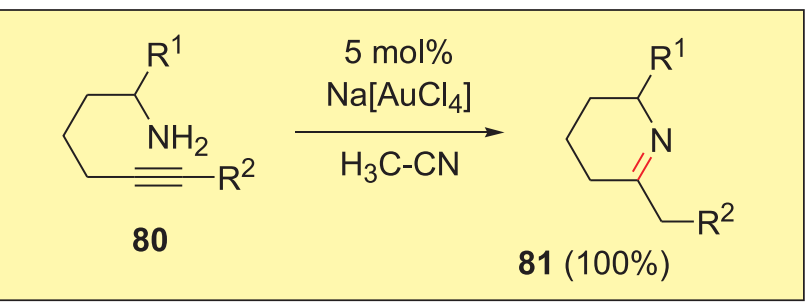

Figure $\mathbf{3 0}$

Intramolecular addition of $\mathrm{N}$-nucleophiles to alkynes

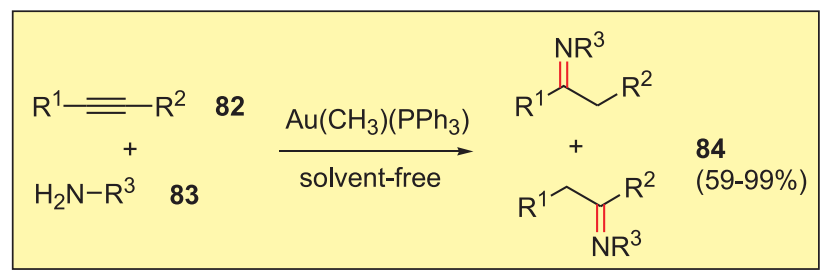

Figure 31

Hydroamination under solvent-free conditions

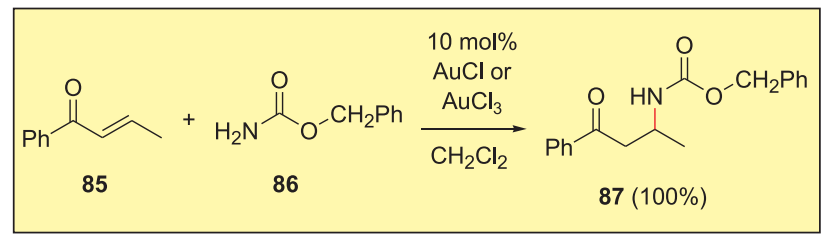

Figure 32

The aza-Michael reaction 
is well known. Utimoto et al. published in 1987 that $\mathrm{Au}(\mathrm{III})$, which has the similar $\mathrm{d}^{8}$-configuration, is much more efficient for the activation of alkynes $\mathbf{8 0}$ for the intramolecular addition of amines $(54,55)$. Consequently nitrogen-heterocycles such as $\mathbf{8 1}$ can be obtained, Figure 30.

T. E. Müller et al. reported that a gold(III)-phosphane complex with a weakly co-ordinating nitrate counter ion was active for the hydroamination of alkynes, but a cationic copper(I)-catalyst possessed the highest activity $(56,57)$.

Lok et al. also used a cationic gold(I) catalyst for the hydroamination to dihydropyrimidine-heterocycles, but $\mathrm{AgBF}_{4}$ had the same activity (58).

Latest results of Tanaka et al. (59) showed that with the combination of $\mathrm{AuCH}_{3}\left(\mathrm{Ph}_{3} \mathrm{P}\right)$ and an acidic promoter [a catalyst system developed by Teles et al. $(69,70)$ for the addition of oxygen-nucleophiles to alkynes and allenes, see Figs 37 and 38], only 0.01 mol\% of catalyst are needed and $86 \%$ yield of 84 could be obtained under solvent-free conditions from 82 and $\mathbf{8 3}$, Figure 31.

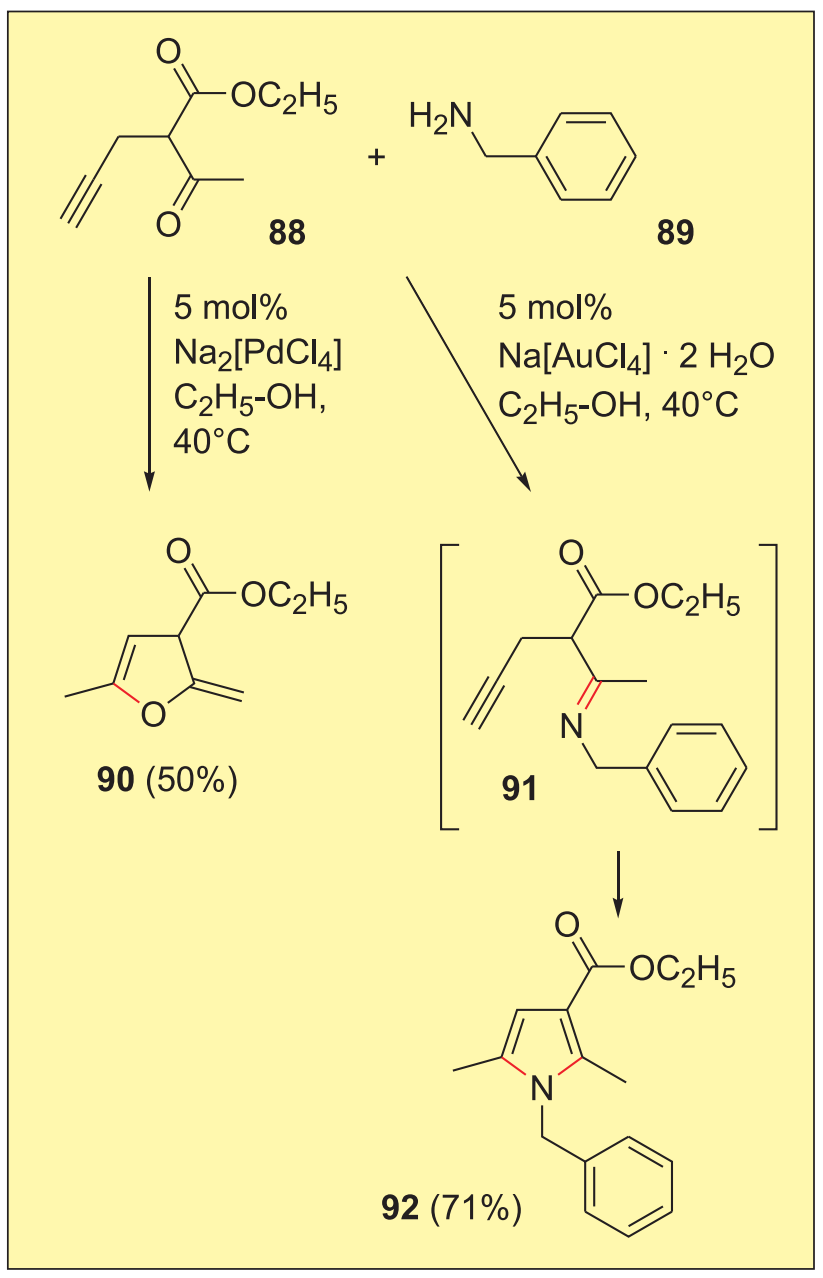

Figure 33

Different heterocycles from the same substrates by the choice of the catalyst
The addition of carbamates 86 to $\alpha, \beta$-unsaturated ketones $\mathbf{8 5}$, the aza-Michael reaction to $\mathbf{8 7}$, could be achieved with 10 mol\% of both $\mathrm{AuCl}$ and $\mathrm{AuCl}_{3}$ (60), Figure 32 .

A variation of the intramolecular addition of $\mathrm{N}$ nucleophiles to alkynes was recently reported by Arcadi et al. (61). They observed that an amine $\mathbf{8 9}$ does not intermolecularly add to the alkyne in $\mathbf{8 8}$ but that $\mathrm{Na}\left[\mathrm{AuCl}_{4}\right] \bullet \mathrm{H}_{2} \mathrm{O}$ catalyses the condensation of the amine with a carbonyl group (62) and then the intramolecular $\mathrm{N}$ nucleophile in $\mathbf{9 1}$ reacts with the alkyne and produces the pyrrole 92, Figure 33. On the other hand, the corresponding Pd-catalyst $\mathrm{Na}_{2}\left[\mathrm{PdCl}_{4}\right]$ does not catalyse the condensation, and the intramolecular addition of the oxygen atom of the aldehyde group gives the oxygen-heterocycle $\mathbf{9 0}$.

The same reaction was also conducted with primary amines possessing a stereogenic centre in the substituent (63). In continuation of this work, the gold-catalysed condensation of 1,3-dicarbonyl compounds 93 with

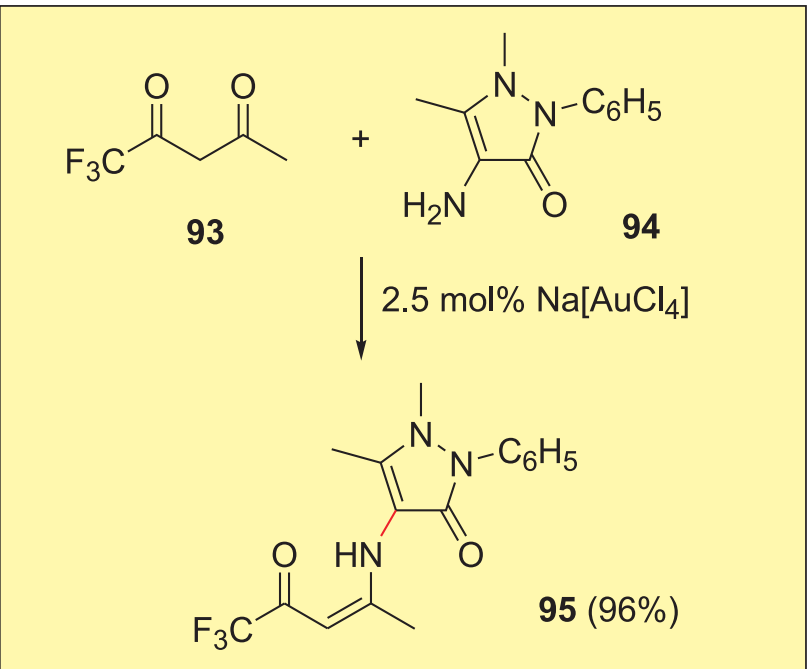

\section{Figure 34}

Selective condensation reactions to give enaminones

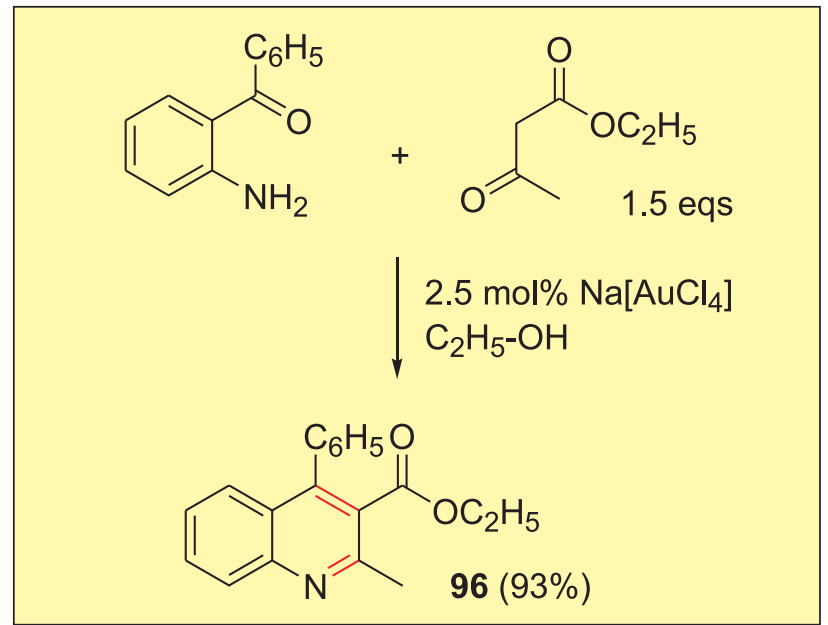

Figure 35

A new synthesis of quinolines 


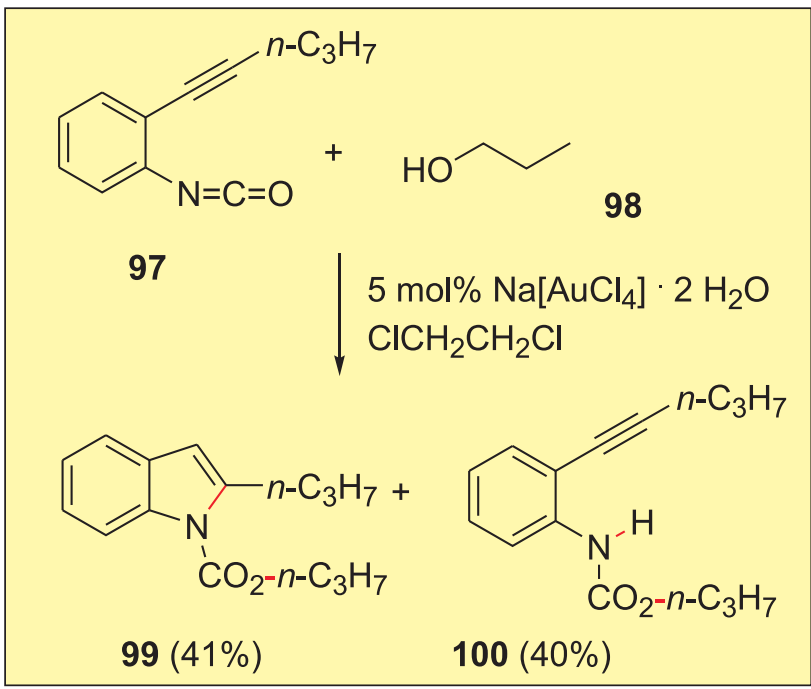

Figure 36

Indoles by gold catalysis

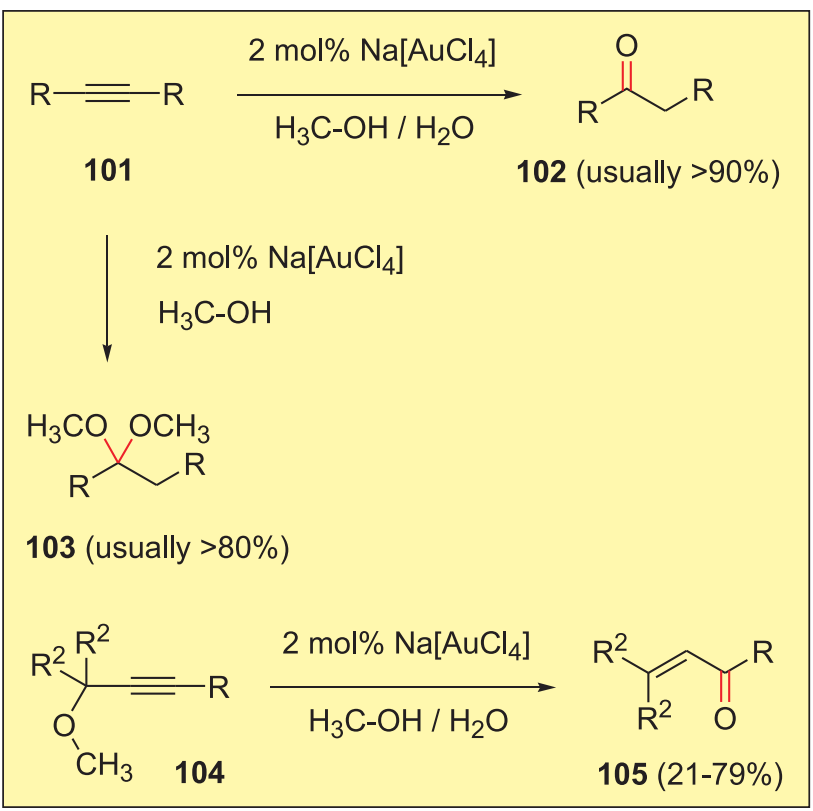

Figure 37

Intermolecular addition of O-nucleophiles to alkynes

nucleophiles was developed (62). Thus, with amines $94 \beta$ enaminones 95 could be obtained under mild conditions in high yields, Figure 34 .

Salts of other metals, such as $\mathrm{Cul}, \mathrm{ZnCl}, \mathrm{AgNO}_{3}$ and $\mathrm{Na}_{2}\left[\mathrm{PdCl}_{4}\right]$ gave significantly lower yields. The reaction could be extended to alcohols, phosphanes and even thiols!

Subsequently, this was extended to an alternative protocol for the Friedländer synthesis of quinolines $\mathbf{9 6}$, a substructure frequently found in pharmacologically active compounds (64), Figure 35. Here neither $\mathrm{Na}_{2}\left[\mathrm{PdCl}_{4}\right]$, Cul nor $\mathrm{AgNO}_{3}$ showed catalytic activity, only $\mathrm{ZnCl}_{2}$ gave some product.

Yamamoto et al. (65) reported that 2-alkynyl phenylisocyanates $\mathbf{9 7}$ and propanol $\mathbf{9 8}$ delivered a mixture of

$\overbrace{\mathrm{R}}^{\mathrm{OCH}_{3}}$

\section{Figure 38}

Enol ethers as side products in the addition of alcohols to alkynes

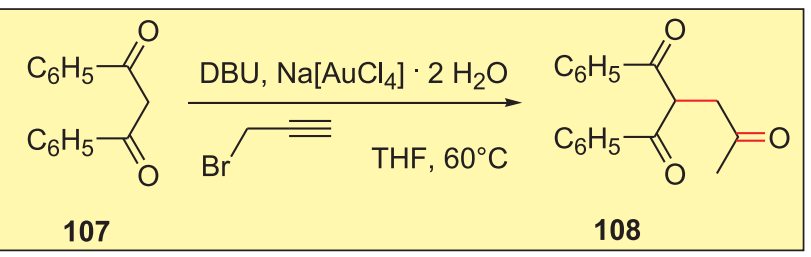

\section{Figure 39}

One-pot alkylation/hydration (DBU = 1,8-diazabicyclo[5.4.0]undec-7 -ene, THF = tetrahydrofuran)

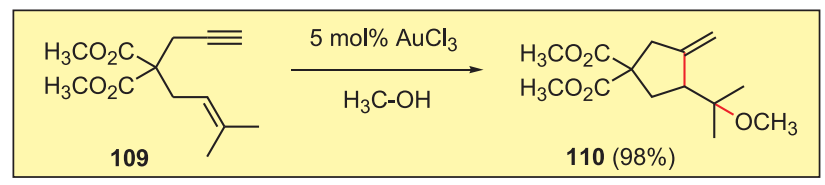

Figure $\mathbf{4 0}$

Inserting an olefin between the alkyne and the nucleophile

indole 99 (C-N-bond formation) and/or carbamate 100 (N-Hbond formation), Figure 36. Both $\mathrm{Na}\left[\mathrm{AuCl}_{4}\right] \cdot 2 \mathrm{H}_{2} \mathrm{O}$ and $\mathrm{AuCl}_{3}$ gave $80 \%$ of a mixture of $\mathbf{9 9}$ and $\mathbf{1 0 0}$ (ratio close to $1: 1$ ), while $\mathrm{Na}_{2}\left[\mathrm{PdCl}_{4}\right]$ gave a $74 \%$ yield of 99 and $\mathrm{Pd}_{2}(\mathrm{dba})_{3} \cdot \mathrm{CHCl}_{3}$ provided $96 \%$ of $\mathbf{1 0 0}$.

Similar additions to alkynes $\mathbf{1 0 1}$ could be achieved in an intermolecular manner with oxygen-nucleophiles such as water (to furnish ketones 102) or alcohols (to furnish ketals 103) $(66,67)$. In unsymmetric alkynes the regioselectivity could be controlled by a neighbouring alkoxy group such as that in 104, which finally gives $\alpha, \beta$-unsaturated ketones 105 (68), Figure 37.

One major breakthrough in this field (and probably in the whole field of gold-catalysis, too) was the discovery published by Teles et al. in 1998. A cationic Au(I) catalyst with phosphane ligands provided ketals such as $\mathbf{1 0 3}$ along with the enol ether $\mathbf{1 0 6}$ from symmetrical alkynes with turnover numbers up to 100,000 and turnover frequencies up to $5,400 / \mathrm{h}(69,70)$, Figure 38 .

These numbers were exceeded by Tanaka, Hayashi et al., who succeeded in triplicating these turnover frequencies to 15,600 by the choice of methanol as the solvent and CO as a co-ligand for the addition of water to alkynes (71). Although the reaction is conducted in aqueous methanol, only the thermodynamically more stable addition product of water, i.e. the ketone, is produced. As expected, the Markovnikovproduct is observed. The TON is orders of magnitude higher than the most efficient catalysts based on other metal derivatives such as cis- $\mathrm{PtCl}_{2}\left[\mathrm{P}\left(m-\mathrm{C}_{6} \mathrm{H}_{4} \mathrm{SO}_{3} \mathrm{Na}\right)_{3}\right]_{2}$ (72). 


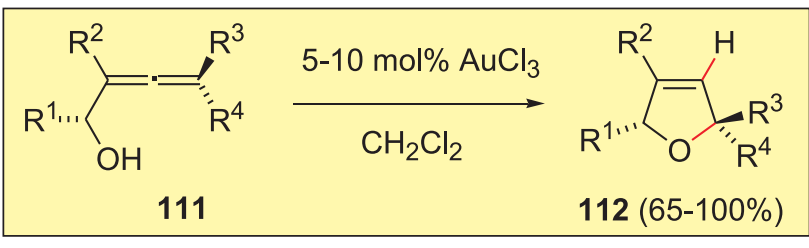

Figure 41

Clean axial to central chirality transfer with allenyl carbinols

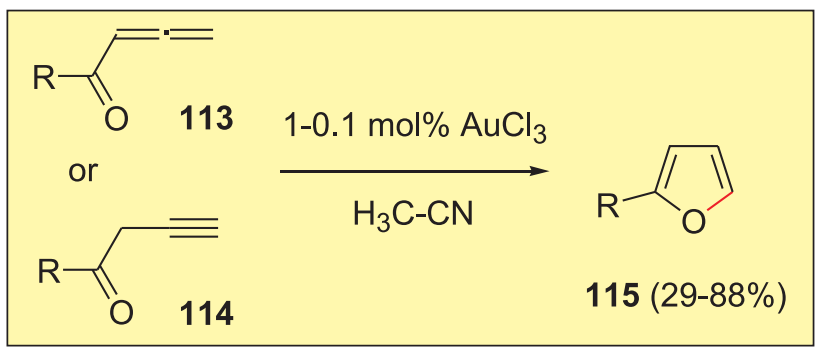

Figure $\mathbf{4 2}$

Ketones as intramolecular oxygen-nucleophiles

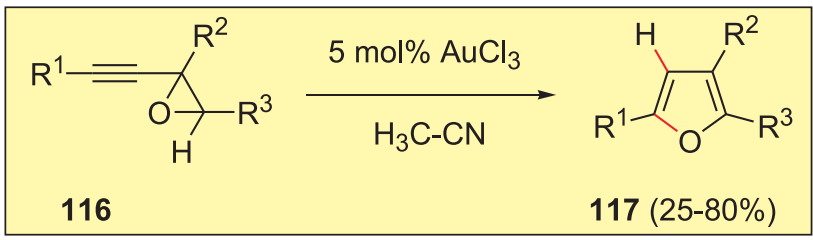

Figure 43

Epoxides as intramolecular oxygen-nucleophiles

Arcadi et al. (73) described the selective monopropargylation of dibenzoylmethane $\mathbf{1 0 7}$ in the presence of DBU (1,8-diazabicyclo[5.4.0]undec-7-ene) followed by a $\mathrm{Na}\left[\mathrm{AuCl}_{4}\right] \cdot 2 \mathrm{H}_{2} \mathrm{O}$-catalysed hydration to the tricarbonyl derivative 108 as a one-pot procedure, Figure 39.

Organometallic thiazolium gold(III)-complexes could also catalyse the hydration of phenylacetylene in ionic liquids (74). The optimum reaction temperature was $30^{\circ} \mathrm{C}$, the 1-butyl-3methylimidazolium triflate in combination with $2.4 \mathrm{~mol} \%$ $\mathrm{Na}\left[\mathrm{AuCl}_{4}\right]$ delivered a yield of up to $75 \%$.

Another example for such gold complexes of $\mathrm{N}$ heterocyclic carbenes being active in the hydration of 3hexyne was provided recently by Herrmann et al. (75).

Most interesting is recent research by M. Laguna et al. (76), who investigated organometallic gold(III) and gold(I) complexes for the addition of water and methanol to alkynes and obtained evidence for gold(III) being the active catalyst.

An olefin is used as a relay for the addition of alcohols to 1,6-enynes 109 catalysed by $\mathrm{AuCl}_{3}$. Echavarren et al. (77) reported that, at least in some examples, the results obtained with $\mathrm{AuCl}_{3}$ were superior to the results observed with $\mathrm{PtCl}_{2}$ for the formation of 110, Figure 40.

A different type of C-C-multiple bond is an allene such as 111. The intramolecular addition of alcohol groups was described by Krause et al. (78). The axial chirality of the allene in $\mathbf{1 1 1}$ unit cleanly transfers to a central chirality in the dihydrofuran 112, Figure 41. This was the method of choice for acid-sensitive substrates which would not survive classical acid-catalysed cyclization.

This reaction was also a key step in the preparation of an important intermediate of Marshall's citreovial synthesis (79). Rather than the almost stoichiometric amounts of $\mathrm{AgNO}_{3}(80$ mol\%) used with silver, only $5 \mathrm{~mol} \% \mathrm{AuCl}_{3}$ was necessary (80).

A related reaction of allenyl ketones $\mathbf{1 1 3}$ to furans $\mathbf{1 1 5}$ had already been reported in 2000 by Hashmi et al. (34); propargyl ketones 114 react in a similar manner, Figure 42.

A further type of oxygen-nucleophile are epoxides, the intramolecular reaction of alkynyl epoxides $\mathbf{1 1 6}$ readily produces furans $\mathbf{1 1 7}$ with a perfect control of the position of the substituents (81), Figure 43.

\section{Reactions with Organoboron Compounds, Dihydrogen, Organostannanes and Organosilanes}

Studies on these reactions were initiated in 1995 by Baker, Westcott et al. (82). This work also provided experimental proof for a principle of gold chemistry deduced much earlier

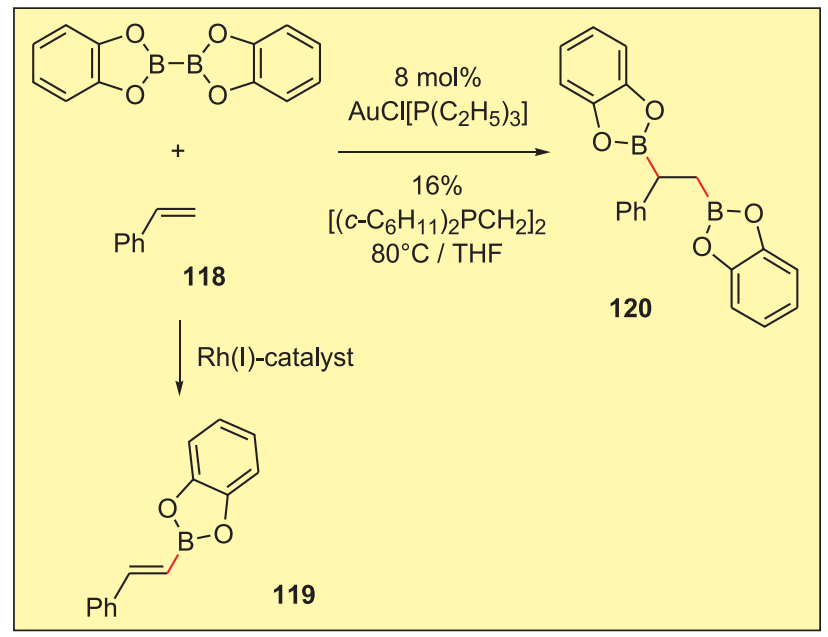

Figure 44

Diborylation of styrenes - no competing $\beta$-H-elimination (THF = tetrahydrofuran)

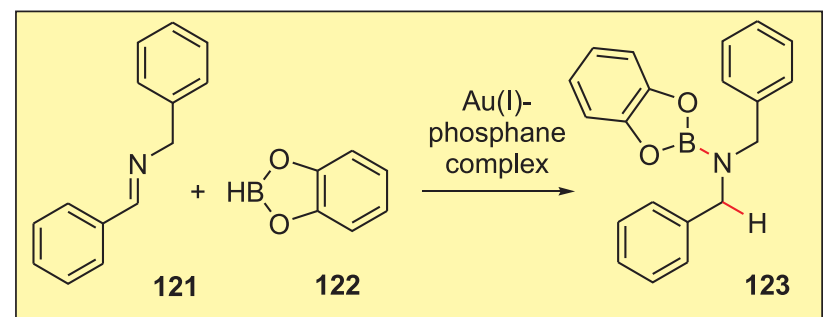

Figure 45

Intermolecular hydroboration of imines 


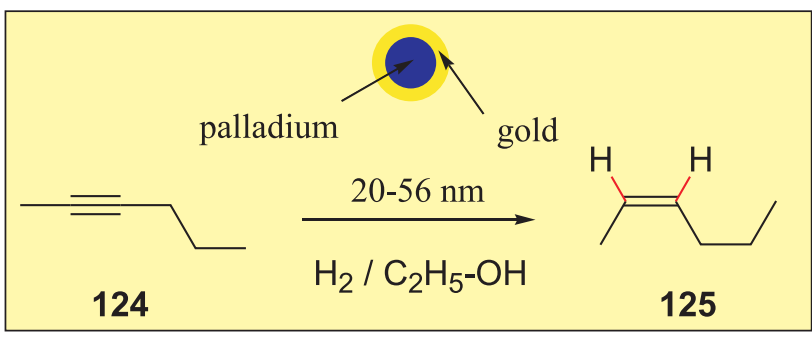

Figure 46

Hydrogenation of alkynes to (Z)-akenes

\begin{tabular}{|c|c|c|c|}
\hline \multirow{2}{*}{2} & & $\begin{array}{c}0.1 \mathrm{~mol} \% \\
\mathrm{Au}\left(\mathrm{CH}_{3}\right)\left(\mathrm{PPh}_{3}\right)\end{array}$ & \\
\hline & 126 & $\begin{array}{c}\text { THF } \\
\text { rt, } 2 \text { days }\end{array}$ & $127(94 \%)$ \\
\hline
\end{tabular}

Figure $\mathbf{4 7}$

Dehydrogenative dimerisation of trialkylstannanes ( $T H F=$ tetrahydrofuran)

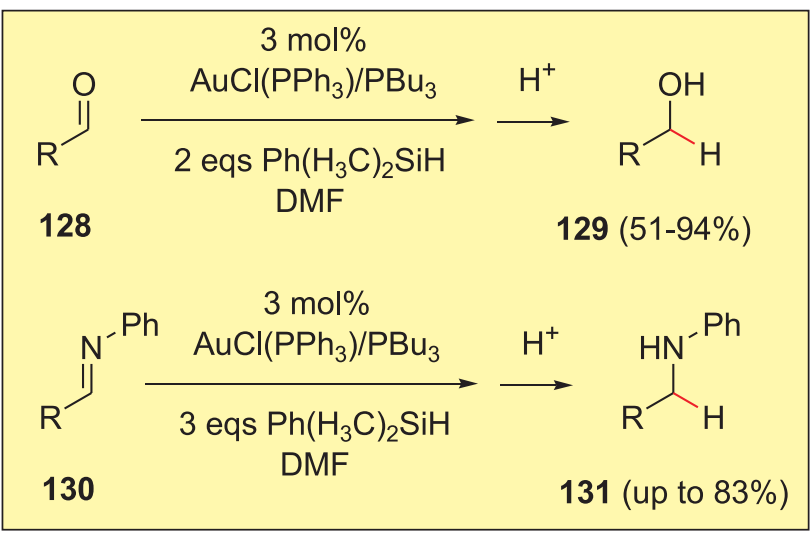

Figure 48

Hydrosilylation of aldehydes and imines

$(\mathrm{DMF}=\mathrm{N}, \mathrm{N}$-dimethylformamide)

from the lack of gold hydrides, i.e. the low tendency to undergo $\beta$-hydride elimination (compare Figure 21). The diborylation of styrenes $\mathbf{1 1 8}$ was unsuccessful with rhodium catalysts, only the vinyl boranes $\mathbf{1 1 9}$ were obtained. But, with the gold(I)-catalyst the diboryl compound $\mathbf{1 2 0}$ was isolated, Figure 44. Most unfortunately no yield is given, so that the turnover number cannot be calculated.

The hydroboration of arylimines 121 with 122 was also possible, the phosphane gold(I)-chloride complex catalysed reaction to give 123, Figure 45: this was more than 40 times faster than the uncatalysed reaction (83).

The selective hydrogenation of alkynes such as $\mathbf{1 2 4}$ to (Z)alkenes $\mathbf{1 2 5}$ is an important topic in organic synthesis. Here, Schmid et al. were quite successful with gold-covered palladium particles of 20-56 nm diameter (84). Up to a conversion of $80 \%$, the selectivity is high for the (Z)-product and these catalysts are more active than the pure metals.
Hexaalkyldistannane is a useful reagent for organic synthesis (85), but it is relatively expensive. This immediately clarifies the importance of the formation of hexabutyldistannane $\mathbf{1 2 7}$ from the relatively inexpensive tributylstannane 126 by dehydrogenative dimerization forming the tin-tin-bond as described by lto et al. in 1999 (86).

In 2000, Hosomi et al. reported the successful hydrosilylation of ketones $\mathbf{1 2 8}$ and imines $\mathbf{1 3 0}$ with $\mathrm{PhMe}_{2} \mathrm{SiH}$ and $3 \mathrm{~mol} \%$ of the $\mathrm{AuCl}(\mathrm{PPh})_{3} / \mathrm{PBu}_{3}$ catalyst (87). After workup, the primary alcohols $\mathbf{1 2 9}$ or the secondary amines 131 could be isolated.

This methodology allows a differentiation between aldehydes and ketones.

\section{Trans/cis-Isomerisation of Pd(II)- Diarylcomplexes}

The trans/cis-isomerisation of square-planar $d^{8}$-complexes had been of interest in co-ordination and organometallic chemistry for a long time. In 1998 Espinet et al. discovered that as little as $0.6 \mathrm{~mol} \%$ of an aryl gold(I)tetrahydrothiophene complex catalyses the isomerisation of the trans-complex 132 to the cis-complex 133 within minutes, while the uncatalysed reaction under the same conditions would take days (88), Figure 49.

\section{Curiosities}

As early as 1990, Herrmann et al. filed an interesting patent, where numerous transition metal complexes, including three gold complexes, of tris(m-sulfonphenyl)phosphate were

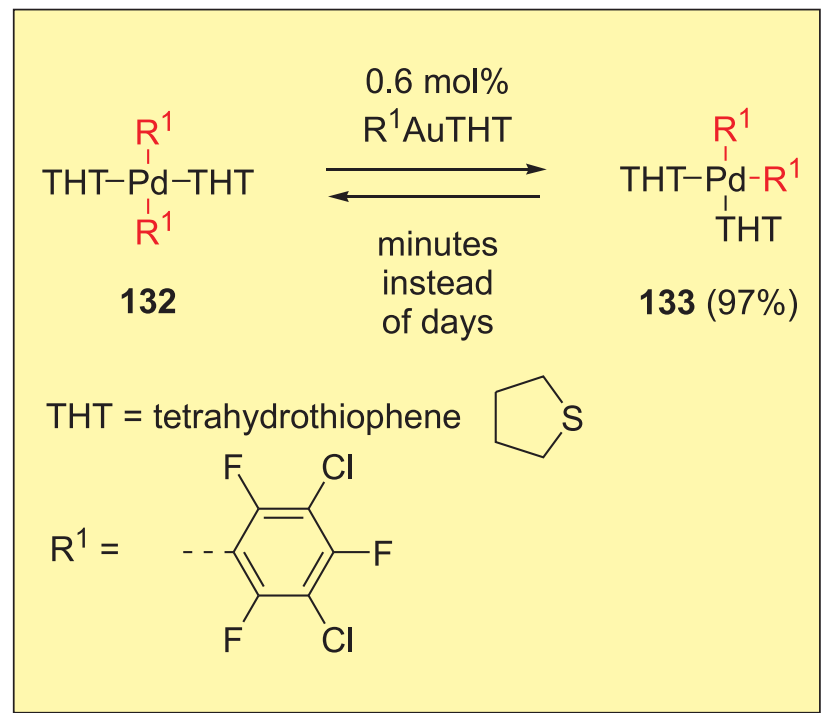

Figure 49

Acceleration of the trans/cis-isomerisation in Pd(II)-complexes 


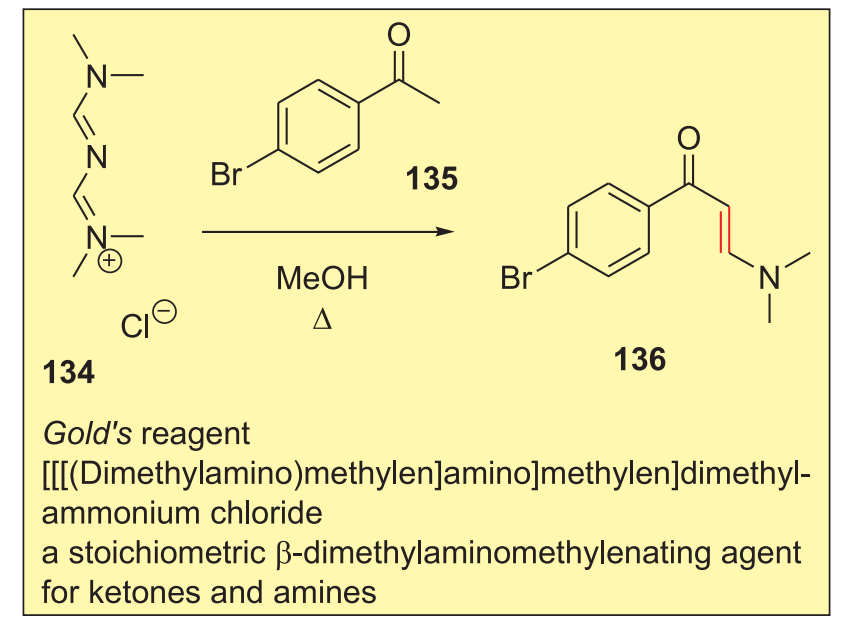

\section{Figure 50}

Gold's reagent does not contain any gold!

prepared $(89,90,91)$. A use as catalysts in homogeneous hydrogenations, the water gas shift reaction, hydroformylations, oxidations, carbon-carbon cross-linking reactions and hydroamination was claimed, but none of the examples for catalysis reactions given in the patent was conducted with gold. With the many reactions known today, it would be quite interesting to look at these complexes again!

There exists a name-reagent, Gold's reagent 134. Remarkably it does not contain the element gold; it is a stoichiometric $\beta$-dimethylaminomethylenating agent for ketones like 135 (to yield 136) or amines (92,93), Figure 50.

\section{Conclusions}

It is obvious that homogeneous catalysis by gold already has numerous applications. Most of these are in the field of organic synthesis (of fine chemicals), and only the reactions in Figure 47 (stannanes) and in Figure 49 (Pd complexes) stem from the field of inorganic synthesis.

Overall, the following 'fundamentals' of homogeneous gold-catalysis can be deduced from the examples above:

1) Gold is a 'soft' transition metal and thus prefers other soft partners, for example carbon (this might explain the dominance of organic chemistry in this field).

2) Gold shows a low tendency for $\beta$-hydride elimination.

3) Gold often reacts much faster than other transition metals which in principle can catalyse the same reaction. Often this higher reactivity cannot only be explained by higher ligand exchange rates. Here theoretical investigation might provide some insight.

4) Organogold intermediates undergo fast protodemetallation.

5) Due to the easy reduction and the difficult oxidation of

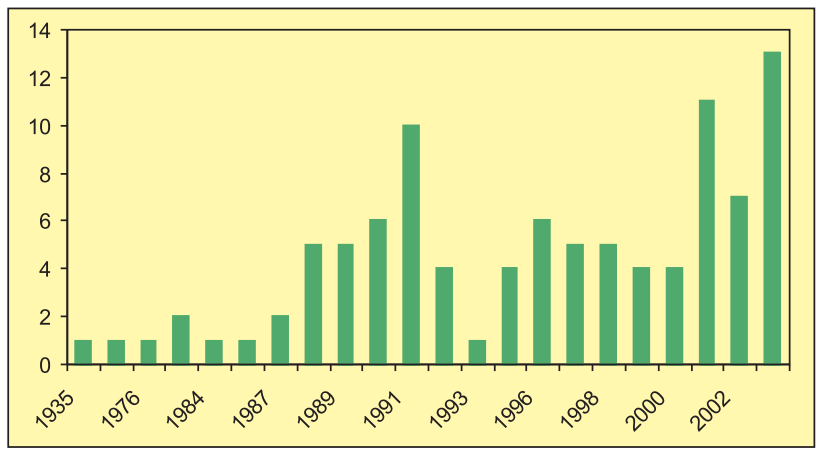

Figure 51

Publications on homogeneous catalysis per year

gold, a cross-coupling chemistry seems to be difficult to reach due to the necessary change of oxidation states and most reactions presented here probably do not go along with oxidation or reduction of the catalytically active gold species in the catalytic cycle $(94,95,96,97)$.

6) In most cases, the mechanism of the reactions, starting with the oxidation state of the catalytically active species, has not yet been established. It is also obvious that often the reactions are possible with both $\mathrm{Au}(\mathrm{I})$ or $\mathrm{Au}(\mathrm{III})$ pre-catalysts and the question of what is the oxidation state of the active species has also not yet been resolved.

Most of the different homogeneous reactions catalysed by gold have been developed in the past four years. The distribution of the papers on homogeneous gold catalysis in time is shown in Figure 51.

One can clearly see two major 'peaks', one was probably initiated in 1986 by Ito and Hayashi's discovery of the asymmetric aldol reaction, the second can be related to both Teles' $(69,70) 1998$ finding of highly active catalysts for the addition of heteronucleophiles to alkynes and the Dyker (98) 'Highlight' paper from 2000 on the C-C-bond formation reactions developed by Hashmi et al. in $2000(34,40)$.

I am confident, that these developments will accelerate in the near future, and that most people working in the field of homogeneous transition metal catalysis will also give gold a chance on a regular basis.

\section{Acknowledgements}

My co-workers Lothar Schwarz, Tanja M. Frost, Li Grundl (Li Ding), Elzen Kurpejovic, Jan Weyrauch, Dirk Fischer, Pradipta Sinha, Ralph Salathé and Matthias Rudolph have added major contributions to the field, many aspects not being cited in this paper. I am also grateful to our sponsors DFG, Fonds der Chemischen Industrie, DAAD, Karl-Ziegler Stiftung and Umicore AG \& Co KG (formerly OMG, dmc ${ }^{2}$, Degussa). 


\section{About the Author}

A. Stephen K. Hashmi is professor of organic chemistry at the Universität Stuttgart. He carried out his Diploma and PhD with Professor G. Szeimies at the Ludwig-MaximiliansUniversität München in the field of strained organic compounds such as bicyclobutanes and propellanes. His postdoctorate research with Professor B. M. Trost at Stanford University, California, covered transition metal catalysis, specifically then enyne metathesis. His Habilitation with Prof. J. Mulzer at the Freie Universität Berlin, the Johann Wolfgang Goethe-Universität Frankfurt and the Universität Wien, Austria, as well as visits at the University of Tasmania, Australia, and the Universität Marburg focused on both stoichiometric organometallic chemistry and transition metal catalysed organic reactions, which are still the major topics in the group. Recently, activities in the field of bioorganometallic chemistry with enantiomerically pure metallacycloalkanes have been added.

\section{References}

1 A. Simmer, Arch. Pharm., 1907, 244, 672-684

2 H. Baggesgaard-Rasmussen, G. Espersen and J. Berger, Dansk Tidsskr. Farm. Suppl., 1956, 2, 9-27

3 H. Schmidbaur, Naturw. Rdsch., 1995, 48, 443-451

4 K. Tanaka, Solvent-free Organic Synthesis, Wiley-VCH, Weinheim, 2003

5 W. Schwemberger and W. Gordon, Chem. Zentralbl., 1935, 106, 514514

6 P.G. Gassman, G.R. Meyer and F.J. Williams, J. Am. Chem. Soc., 1972, 94, 7741-7748

7 L.-U. Meyer and A. de Meijere, Tetrahedron Lett., 1976, 497-500

8 F. Herrmann, Ber. Dtsch. Chem. Ges., 1905, 38, 2813-2825

9 F. Gasparrini, M. Giovannoli, D. Misiti, G. Natile and G. Palmieri, Tetrahedron, 1983, 39, 3181-3184

10 F. Gasparrini, M. Giovannoli, D. Misiti, G. Natile and G. Palmieri, Tetrahedron, 1984, 40, 165-170

11 F. Gasparrini, M. Giovannoli, D. Misiti, G. Natile and G. Palmieri, J. Org. Chem., 1990, 55, 1323-1328

12 E. Boring, Y.V. Geletii and C.L. Hill, J. Am. Chem. SoC., 2001, 123, 16251635

13 D.P. Riley, Inorg. Chem., 1983, 22, 1965-1967

14 D.P. Riley, M.R. Smith, P.E. Correa, J. Am. Chem. Soc., 1988, 110, $177-$ 180

15 F. Gasparrini, M. Giovannoli, D. Misiti, G. Natile, G. Palmieri and L. Maresca, J. Am. Chem. Soc., 1993, 115, 4401-4402

16 F. Shi, Y. Deng, H. Yang and T. SiMa, J. Chem. Soc., Chem. Commun., 2001, 345-346

17 F. Shi and Y. Deng, J. Chem. Soc., Chem. Commun., 2001, 443-444

18 G.B. Shul'pin, A.E. Shilov and G. Süss-Fink, Tetrahedron Lett., 2001, 42, 7253-7256
19 J. Sundermeyer and C. Jost, DE 100415101999 [Chem. Abs., 2001, 134, 280723]

20 A. von Baeyer and V. Villiger, Ber. Dtsch. Chem. Ges., 1899, 32, $3622-$ 3633

21 L.A. Levchenko, A.P. Sadkon, N.V. Lariontseva, E.M. Koldasheva, A.K. Shilova and A.E. Shilov, J. Inorg. Biochem., 2002, 88, 251-253

22 Y. Ito, M. Sawamura and T. Hayashi, J. Am. Chem. Soc., 1986, 108, 6405-6406

23 M. Sawamura and Y. Ito, Chem. Rev., 1992, 92, 857-871

24 S.D. Pastor in Encyclopedia of Reagents for Organic Synthesis (Ed. L.A. Paquette), Vol. 1, Wiley, Chichester, 1995, 447-450

25 M. Sawamura and Y. Ito in Catalytic Asymmetric Synthesis (Ed. I. Ojima), First edition, VCH, 1993, 367-388; Second edition, Wiley-VCH, New York, 2000, 493-512

26 X.-T. Zhou, Y.-R. Lin and L.-X. Dai, Tetrahedron Assym., 1999, 10, 855862

27 D. Li, C.-M. Che, H.-L. Kwong and V.W.-W. Yam, J. Chem. Soc., Dalton Trans., 1992, 3325-3329

28 S. Komiya, T. Sone, Y. Usui, M. Hirano and A. Fukuoka, Gold Bull., 1996, 29, 131-136

29 Q. Xu, Y. Imamura, M. Fujiwara and Y. Souma, J. Org. Chem., 1997, 62, 1594-1598

30 G. Wagner, W. Brickner, Ber. Dtsch. Chem. Ges., 1899, 32, 2302-2325

31 H. Meerwein, Liebigs Ann. Chem., 1918, 417, 255-277

32 G. Kaup, Top. Curr. Chem., 1988, 146, 57-98

33 H. Koch, W. Haaf, Angew. Chem., 1958, 70, 311-311

34 A.S.K. Hashmi, L. Schwarz, J.-H. Choi and T.M. Frost, Angew. Chem., 2000, 112, 2382-2385; Angew. Chem. Int. Ed., 2000, 39, 2285-2288

35 A.S.K. Hashmi, Angew. Chem., 2000, 112, 3737-3740; Angew. Chem. Int. Ed., 2000, 39, 3590-3593

36 A. de Meijere, Angew. Chem., 1994, 106, 2473-2506; Angew. Chem. Int. Ed., 1994, 33, 2379-2411

37 For the recent description of gold hydride anions and a discussion of the problems with gold hydrides, see: X. Wang and L. Andrews, Angew. Chem., 2003, 115, 5359-5364; Angew. Chem. Int. Ed., 2003, 42, 5201-5206

38 G. Dyker, E. Muth, A.S.K. Hashmi and L. Ding, Adv. Synth. Catal., 2003, 345, 1247-1252

39 A.S.K. Hashmi, Gold Bull., 2003, 36, 3-9

40 A.S.K. Hashmi, T.M. Frost and J.W. Bats, J. Am. Chem. Soc., 2000, 122, 11553-11554

41 A.S.K. Hashmi, T.M. Frost and J.W. Bats, Catal. Today, 2001, 72, 19-72

42 A.S.K. Hashmi, T.M. Frost and J.W. Bats, Org. Lett., 2001, 3, 3769-3771

43 A.S.K. Hashmi, L. Ding, J.W. Bats, P. Fischer and W. Frey, Chem. Eur. J., 2003, 9, 4339-4345

44 E. Kurpejovic, Universität Stuttgart, recent results during PhD research

45 R. Salathé, Universität Stuttgart, results from Diploma Thesis and recent results during $\mathrm{PhD}$ research

46 J.W. Dankwardt, Tetrahedron Lett., 2001, 42, 5809-5812

47 A. Fürstner, V. Mamane, J. Org. Chem., 2002, 67, 6264-6267

48 G. Abbiati, A. Arcadi, G. Bianchi, S. Di Giuseppe, F. Marinelli and E. Rossi, J. Org. Chem., 2003, 68, 6959-6966 
49 N. Asao, K. Takahashi, S. Lee, T. Kasahara and Y. Yamamoto, J. Am. Chem. Soc., 2002, 124, 12650-12561

50 N. Asao, T. Nogami, S. Lee and Y. Yamamoto, J. Am. Chem. Soc., 2003, 125, 10921-10925

51 G. Dyker, D. Hildebrandt, J. Liu and K. Merz, Angew. Chem., 2003, 115, 4536-4538; Angew. Chem. Int. Ed., 2003, 42, 4399-4402

52 M.T. Reetz and K. Sommer, Eur. J. Org. Chem., 2003, 3485-3496

53 C. Wei and C.-J. Li, J. Am. Chem. Soc., 2003, 125, 9584-9585

54 Y. Fukuda, K. Utimoto and H. Nozaki, Heterocycles, 1987, 25, 297-300

55 Y. Fukuda and K. Utimoto, Synthesis, 1991, 975-978

56 T.E. Müller, Tetrahedron Lett., 1998, 39, 5961-5962

57 T.E. Müller, M. Grosche, E. Herdtweck, A.-K. Pleier, E. Walter and Y.-K. Yan, Organometallics, 2000, 19, 170-183

58 R. Lok, R.E. Leone and A.J. Williams, J. Org. Chem., 1996, 61, 32893297

59 E. Mizushima, T. Hayashi and M. Tanaka, Org. Lett., 2003, 5, 3349-3352

60 S. Kobayashi, K. Kakumoto and M. Sugiura, Org. Lett., 2002, 4, 13191322

61 A. Arcadi, S. Di Giuseppe, F. Marinelli and E. Rossi, Adv. Synth. Catal., 2001, 343, 443-446

62 A. Arcadi, G. Bianchi, S. Di Guiseppe and F. Marinelli, Green Chem., 2003, 5, 64-67

63 A. Arcadi, S. Di Giuseppe, F. Marinelli and E. Rossi, Tetrahedron Asymm., 2001, 12, 2715-2720

64 A. Arcadi, M. Chiarini, S. Di Giuseppe and F. Marinelli, Synlett, 2003, 203206

65 S. Kamijo and Y. Yamamoto, J. Org. Chem., 2003, 68, 4764-4771

66 Y. Fukuda and K. Uchimoto, JP 04103552, 1992 [Chem. Abstr., 1992, 117, 150554]

67 Y. Fukuda and K. Utimoto, J. Org. Chem., 1991, 56, 3729-3731

68 Y. Fukuda and K. Utimoto, Bull. Chem. Soc. Jpn., 1991, 64, 2013-2015

69 J.H. Teles and M. Schulz (BASF AG), WO-A1 9721648, 1997 [Chem. Abstr., 1997, 127, 121499]

70 J.H. Teles, S. Brode and M. Chabanas, Angew. Chem., 1998, 110, 14751478; Angew. Chem. Int. Ed., 1998, 37, 1415-1418

71 E. Mizushima, K. Sato, T. Hayashi and M. Tanaka, Angew. Chem., 2002, 114, 4745-4747; Angew. Chem. Int. Ed., 2002, 41, 4563-4565

72 L.W. Francisco, D.A. Moreno, J.D. Atwood, Organometallics, 2001, 20, 4237-4245

73 A. Arcadi, G. Cerichelli, M. Chiarini, S. Di Giuseppe and F. Marinelli, Tetrahedron Lett., 2000, 41, 9195-9198
74 M. Detlefs, H.G. Raubenheimer and M.W. Esterhuysen, Catal. Today, 2002, 72, 29-41

75 S.K. Schneider, W.A. Herrmann, E. Herdtweck, Z. Anorg. Allg. Chem., 2003, 629, 2363-2370

76 R. Casado, M. Contel, M. Laguna, P. Romero and S. Sanz, J. Am. Chem. Soc., 2003, 123, 11925-11935

77 M. Méndez, M.P. Munoz, C. Nevade, D.J. Cárdenas, A.M. Echavarren, J. Am. Chem. Soc., 2001, 123, 10511-10520

78 A. Hoffmann-Röder and N. Krause, Org. Lett., 2001, 3, 2537-2538

79 J.A. Marshall and K.G. Pinney, J. Org. Chem., 1993, 58, 7180-7184

80 N. Krause, A. Hoffmann-Röder and J. Cansius, Synthesis, 2002, 17591774

81 A.S.K. Hashmi and P. Sinha, Adv. Synth. Catal., 2004, 346, 432-438

82 R.T. Baker, P. Nguyen, T.B. Marder and S.A. Westcott, Angew. Chem., 1995, 107, 1451-1452; Angew. Chem. Int. Ed. Engl., 1995, 34, 13361338

83 R.T. Baker, J.C. Calabrese and S.A. Westcott, J. Organomet. Chem., 1995, 498, 109-117

84 G. Schmid, H. West, J.-O. Malm, J.-O. Bovin and C. Grenthe, Chem. Eur. J., 1996, 2, 1099-1103

85 T.N. Mitchell in Encyclopedia of Reagents for Organic Synthesis (Ed. L.A. Paquette), Vol. 4, Wiley, Chichester, 1995, 2664-2666

86 H. Ito, T. Yajima, J.-i. Tateiwa and A. Hosomi, Tetrahedron Lett., 1999, 40, 7807-7810

87 H. Ito, T. Yajima, J.-i. Tateiwa and A. Hosomi, J. Chem. Soc., Chem. Commun. 2000, 981-982

88 A.L. Casado and P. Espinet, Organometallics, 1998, 17, 3677-3683

89 W.A. Herrmann, J. Kulpe, J. Kellner and H. Riepl, DE 38406001990 [Chem. Abstr., 1991, 114, 43174]

90 W.A. Herrmann, J. Kulpe, J. Kellner and H. Riepl, EP 3723131990 [Chem. Abstr., 1991, 114, 143702]

91 W.A. Herrmann, J. Kulpe, J. Kellner and H. Riepl, US 5,057,618 1991

92 J.T. Gupton, Aldrichim. Acta, 1986, 19, 43-46

93 J.T. Gupton and S.A. Petrich in Encyclopedia of Reagents for Organic Synthesis (Ed. L.A. Paquette), Vol. 3, Wiley, Chichester, 1995, 2014-2016

94 R.V. Parish, Gold Bull., 1997, 30, 3-12

95 R.V. Parish, Gold Bull., 1997, 30, 55-62

96 R.V. Parish, Gold Bull., 1998, 31, 14-21

97 J.J. Pesek and W.R. Manson, Inorg. Chem., 1983, 22, 2958-2959

98 G. Dyker, Angew. Chem., 2000, 112, 4407-4409; Angew. Chem., 2000, 39, 4237-4239 